\title{
Excitation and Inhibition Imbalance in Rett Syndrome
}

Wei Li*

Department of Neurobiology, University of Alabama at Birmingham, Birmingham, AL, United States

A loss of the excitation/inhibition (E/I) balance in the neural circuit has emerged as a common neuropathological feature in many neurodevelopmental disorders. Rett syndrome (RTT), a prevalent neurodevelopmental disorder that affects 1:10,000-15,000 women globally, is caused by loss-of-function mutations in the Methyl-CpG-binding Protein-2 (Mecp2) gene. E/I imbalance is recognized as the leading cellular and synaptic hallmark that is fundamental to diverse RTT neurological symptoms, including stereotypic hand movements, impaired motor coordination, breathing irregularities, seizures, and learning/memory dysfunctions. E/I balance in RTT is not homogeneously altered but demonstrates brain region and cell type specificity instead. In this review, I elaborate on the current understanding of the loss of E/I balance in a range of brain areas at molecular and cellular levels. I further describe how the underlying cellular

OPEN ACCESS

Edited by: Claudia Fuchs,

University of Bologna, Italy

Reviewed by:

Wen Zhang,

Peking University, China

Xavier Leinekugel,

Institut National de la Santé et de la

Recherche Médicale (INSERM),

France

*Correspondence:

Wei Li

weili7@uab.edu

Specialty section: This article was submitted to

Neurodevelopment,

a section of the journal

Frontiers in Neuroscience

Received: 29 November 2021

Accepted: 31 January 2022

Published: 18 February 2022

Citation:

Li W (2022) Excitation and Inhibition Imbalance in Rett

Syndrome.

Front. Neurosci. 16:825063. doi: 10.3389/fnins.2022.825063 mechanisms contribute to the disturbance of the proper E/I ratio. Last, I discuss current pharmacologic innervations for RTT and their role in modifying the E/I balance.

Keywords: excitation/inhibition balance, MeCP2, Rett syndrome, synaptic transmission, neurodevelopmental disorder

\section{INTRODUCTION}

Rett syndrome (RTT; OMIM identifier \#312750), a neurodevelopmental disorder, is the leading cause of intellectual disabilities in girls in 1:10,000-15,000 births (Armstrong, 2005; Laurvick et al., 2006; Chahrour and Zoghbi, 2007). More than $95 \%$ of RTT cases are caused by loss-of-function mutations in the X-linked gene encoding a transcriptional regulator known as methyl-CpG-binding protein 2 (MeCP2). Individuals with RTT appear to develop typically until 6-18 months, when a constellation of neurological symptoms emerge, including autism-like behaviors, stereotypic hand movements, aberrant visual contacts, breathing irregularities, seizures, and loss of acquired speech (Hagberg et al., 1983; Neul et al., 2010).

More than two decades of intensive research in RTT has revolutionized our understanding of its pathogenesis since MeCP2 was discovered as a key culprit. It was first hypothesized that $\mathrm{MeCP} 2$ functions as a transcriptional repressor by targeting DNA at CpG inlands (Nan et al., 1997; Jones et al., 1998). Later findings suggest that MeCP2 also has a role in gene activation and exhibits widespread binding distribution across target genes (Chen et al., 2015; Horvath and Monteggia, 2018; Lee et al., 2020). MeCP2 is prevalently expressed in the brain and its deficiency in neurons was initially regarded as the exclusive cause of RTT (Chahrour and Zoghbi, 2007). However, later studies found that non-neuronal cells, including glia, have a pathological role in RTT etiology (Lioy et al., 2011). Furthermore, MeCP2 was thought to be only essential for brain development, but conditional mouse models of RTT show similar symptoms when MeCP2 is deleted during adulthood. These abnormalities can be reversed by re-expression of MeCP2 in adult 
mice (McGraw et al., 2011; Cheval et al., 2012; Robinson et al., 2012). These discoveries suggest that $\mathrm{MeCP} 2$ is not only required for brain development but also for maintaining intact neural function throughout the life span. In terms of the onset of symptoms, many subtle neurological aberrances in RTT patients occur earlier than neuroscientists initially thought, pointing out that the clinical manifestations seem to be a result of a gradual accumulation of brain pathology rather than a rapid deterioration (Einspieler et al., 2005; Marschik et al., 2013). In search of underlying cellular dysfunction, researchers started to acknowledge the loss of excitation/inhibition (E/I) balance as a fundamental mechanism underlying this disorder (Ip et al., 2018). Excitatory and inhibitory synapses undergo spatial and temporal modification during the postnatal development; E/I balance needs to be dynamically maintained for the neural circuit to function properly (Niciu et al., 2012; Oh and Smith, 2019). Understanding the cause and consequence of the unbalanced $\mathrm{E} / \mathrm{I}$ in RTT is undoubtfully a crucial step for seeking or evaluating any therapeutic interventions.

In the first part of this review, I will elucidate the characteristics of two central E/I components in different brain areas: glutamatergic activity and GABAergic activity. I will also discuss several critical elements, which can pose a significant impact on E/I balance. The second part of this review will detail the consequence of $\mathrm{E} / \mathrm{I}$ imbalance on brain function at the synaptic and network levels. Lastly, I will elaborate on several ongoing pharmacological treatments and their impact on E/I balance. Of note, although RTT mostly affects female individuals, the majority of animal studies use male Mecp2 hemizygous knockout $(\mathrm{KO})$ mice to investigate the consequence of Mecp2 deletion on genetic, molecular, cellular, and circuit mechanisms. This choice takes into consideration the fact that the complete absence of MeCP2 in males will allow unambiguous interpretations of the observed results without the potential confounding contribution of wildtype (WT) cells in the mosaic brain of female Mecp2 mice. However, more recent studies, especially those investigating therapeutic treatments, have adopted female heterozygous (HET) mice as they better recapitulate the pathogenesis of human RTT. Even though both genotypes share many similar pathophysiological manifestations, they do display some differences that are of significance for further basic and translational research. For detailed comparisons between two genotypes, I refer readers to a recent review (Ribeiro and MacDonald, 2020). In this discussion, to distinguish them wherever possible, I denote male Mecp2-deficient mice as Mecp2 $\mathrm{KO}$ mice and female mice as Mecp2 HET mice. Additionally, many mouse models have been utilized in RTT research. I will present abbreviated strain names if provided in the original articles; for the full strain names and their genetic background, see our previous review (Li and Pozzo-Miller, 2012).

\section{BRAIN REGION-SPECIFIC LOSS OF EXCITATION/INHIBITION BALANCE}

Studies in the entire brain have been used to determine E/I imbalance in RTT. For example, immunoblotting assay shows that expressions of gamma aminobutyric acid type A receptor $\left(\mathrm{GABA}_{A} \mathrm{R}\right)$ subunit $\beta 3$ and $\mathrm{GABA}_{B} \mathrm{R} 2$ are reduced in brain tissues of RTT patients and many MeCP2-deficient mouse models (Samaco et al., 2004; Nguyen et al., 2012). As measured by magnetic resonance spectroscopy (MRS), the mean glutamate is larger in RTT patients than controls (Horská et al., 2009). By contrast with the higher glutamate concentration, whole-brain homogenates prepared from Mecp2 KO mice (Bird line) show reductions in two glutamate receptors (GluRs) aminomethylphosphonic acid receptor (AMPAR) and $N$-methylD-aspartate receptor (NMDAR), and in two synaptic vesicle proteins glutamate transporter (vGlut) and synapsin (Nguyen et al., 2012). Furthermore, the expression of NMDAR subunits GluN1 and GluN2A is increased, but that of GluN2B is unchanged in Mecp2 KO mice (Bird line) (Maliszewska-Cyna et al., 2010). These incongruities are likely as a study using c-fos expression as a surrogate of neuronal activity shows that the whole-brain activity is not homogenous, with the forebrain tending to be hypoactive and the hindbrain being hyperactive (Kron et al., 2012). Considering this concept, I will discuss the $\mathrm{E} / \mathrm{I}$ imbalance below in a brain region-specific fashion (Table 1). Even in the same brain region, different types of cells may have a drastically distinct role in E/I balance. For instance, mice lacking $\mathrm{MeCP} 2$ in somatostatin-positive (SOM+) interneurons develop seizures but display normal memory and social interaction; in contrast, mice lacking $\mathrm{MeCP} 2$ in parvalbumin-positive $(\mathrm{PV}+)$ interneurons do not exhibit epileptic activity but rather show cognitive deficits (Ito-Ishida et al., 2015). Additionally, various mutations in RTT patients and many different RTT animal models are analyzed, which could account for some controversies. If needed, these aspects will be mentioned in the following discussions.

\section{Excitation/Inhibition Imbalance in the Cerebral Cortex}

One of the first studies was to test neural activity in the motor cortex of human RTT subjects (Eyre et al., 1990). This study demonstrates that muscle responses are normal with electromagnetic stimulation in the cervical spinal cord, whereas they have a low threshold, a short latency, and a protracted duration, suggesting hyperactivity in the motor cortex. The propensity for neural excitation in this brain region was recently confirmed in a larger sample of RTT patients. This study postulates that the increased excitability is caused by dysfunction of GABAergic activity (Bernardo et al., 2020). On the contrary, animal studies in the sensorimotor cortex of Mecp2 KO mice (Jaenisch line) show that evoked excitatory postsynaptic currents (eEPSCs) are reduced in pyramidal neurons of layer 5 (Tropea et al., 2009). This reduction is associated with the postsynaptic deficit, as the amplitude of spontaneous EPSCs (sEPSCs) and immunoreactivity for postsynaptic density protein 95 (PSD95) are both decreased. However, it does not exclude the possibility of presynaptic impairment, because action potential-dependent sEPSCs also rely on presynaptic activity. Immunohistochemical assay for a presynaptic marker could lead to a decisive conclusion. In a different study, examination of Glu uncaging-evoked EPSCs 
TABLE 1 | Excitation/inhibition (E/I) imbalance in the different brain regions of RTT patients or mice.

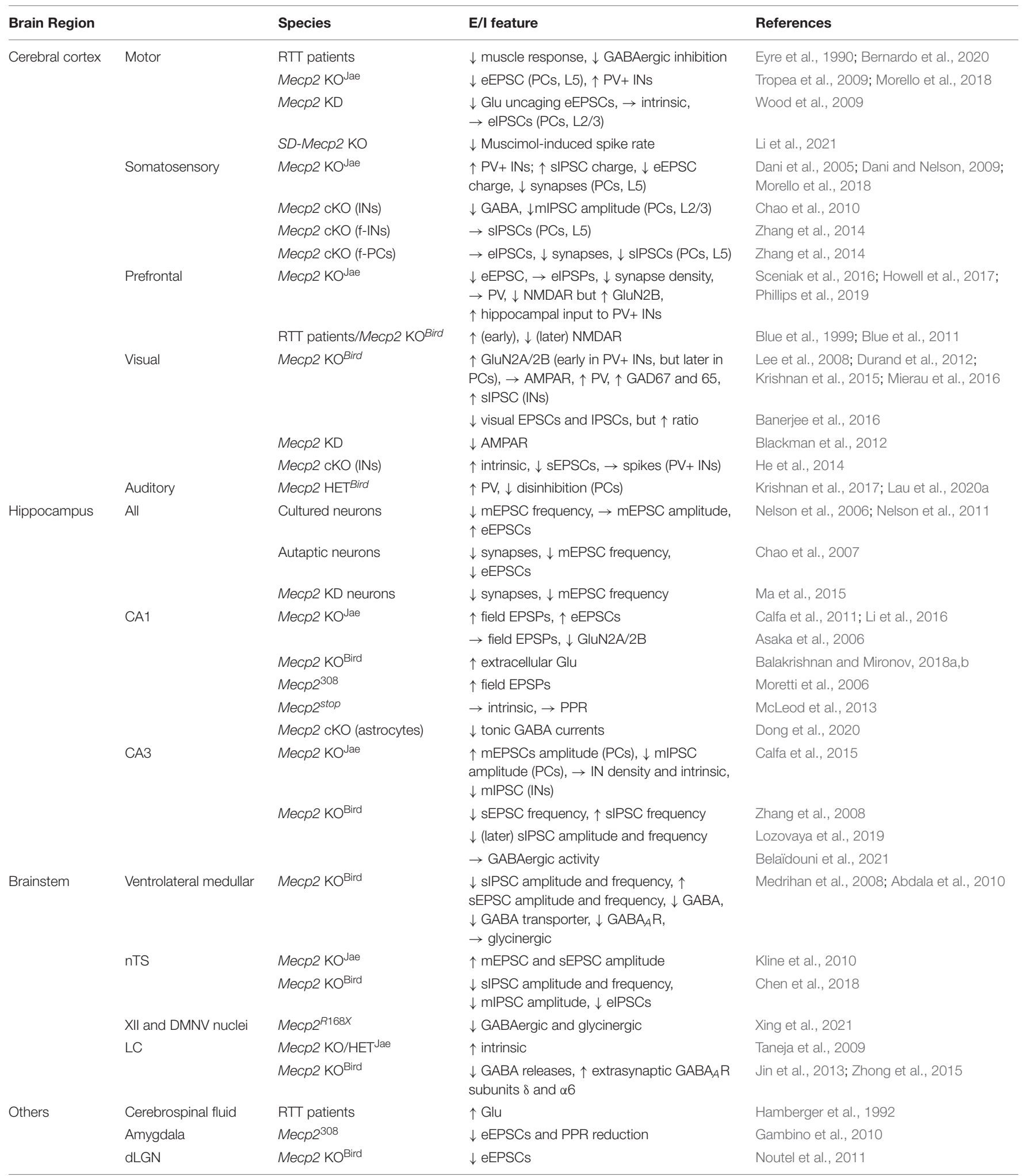

For detailed description, see the text. nTS, nucleus tractus solitarius; LC, locus coeruleus; dLGN, dorsal lateral geniculate nucleus; Jae, Jaenisch line; IN, interneuron; f-INs, forebrain interneurons; f-PCs, forebrain pyramidal cells; PV, parvalbumin; PC, pyramidal cell; Glu, glutamate. SD-Mecp2 KO, Sprague Dawley rat model of Mecp2 knockout. 
in layers $2 / 3$ of the motor cortex demonstrates that synaptic input from layers $3 / 5 \mathrm{~A}$ is reduced following RNA interferencemediated Mecp2 knockdown (KD) in pyramidal neurons (Wood et al., 2009). The topographic distribution of synapses in these layers remains intact; intrinsic properties and inhibitory inputs are also normal in these MeCP2-deficient neurons. Nevertheless, $\mathrm{PV}+$ interneurons that provide the GABAergic inhibition in the motor and somatosensory cortices are increased in density, resulting in a reduced network activity as measured by voltagesensitive dye imaging (Morello et al., 2018). Consistent with this result, multi-unit recordings in the motor cortex reveal an increased synaptic inhibition in a rat model of RTT (Li et al., 2021). Collectively, more studies in the motor cortex are needed to resolve the discrepancy of findings in human RTT and animal models.

In the somatosensory cortex, the number of PV+ interneurons is increased (Morello et al., 2018). Congruently, spontaneous inhibitory postsynaptic currents (sIPSCs) in pyramidal neurons are augmented in charge transfer (Dani et al., 2005). Together with the increased inhibitory activity, the decreased charge of eEPSCs contributes to a reduction of neuronal discharge in layer 5 pyramidal neurons. The same group further demonstrates that the decreased excitatory neurotransmission is caused by the low number of synaptic contacts (Dani and Nelson, 2009). Furthermore, the amplitude and frequency of action potentialindependent miniature $(\mathrm{m})$ EPSCs are decreased but those of mIPSCs are normal, indicating that pre- and postsynaptic machinery is affected in the excitatory but not the inhibitory synapses (Dani et al., 2005). Compared to these results obtained from constitutive Mecp2 KO mice (Jaenisch line), Mecp2 deletion solely in GABAergic interneurons results in lower GABA content and smaller mIPSCs in layers $2 / 3$ pyramidal neurons (Chao et al., 2010). Restoring MeCP2 expression in GABAergic interneurons alone is sufficient to alleviate these molecular and cellular deficits found in constitutive Mecp2 KO mice (Ure et al., 2016). However, forebrain-specific Mecp2 deletion from interneurons does not affect sIPSPs in layer 5 (Zhang et al., 2014); it may affect other aspects of synaptic transmission because these animals display some RTT-like features (Chao et al., 2010). Interestingly, selective deletion of Mecp2 from excitatory neurons has no effect on excitatory transmission but instead reduces inhibitory synapse numbers and neurotransmission in the somatosensory cortex and the prefrontal cortex (Zhang et al., 2014). Altogether, the different results obtained from constitutive and conditional $\mathrm{KO}$ mice suggest the possible compensation during the development.

In Mecp2 $\mathrm{KO}$ mice, the prefrontal cortex shows an amplitude reduction in eEPSCs but normal eIPSCs, which is consistent with the reduced density of excitatory synapses and normal PV expression (Sceniak et al., 2016; Howell et al., 2017). The total levels of NMDARs are decreased, but the relative fraction of one subunit, GluN2B, is conversely increased. In RTT patients and Mecp2 KO mice (Bird line), NMDAR expression in the prefrontal cortex also declines at a later age following an initial increase (Blue et al., 1999; Blue et al., 2011). In addition to the cortical origin, hypoactivity in the prefrontal cortex may be partially caused by hyperactive hippocampal input that preferentially targets $\mathrm{PV}+$ interneurons in Mecp2 $\mathrm{KO}$ mice (Jaenisch line) (Phillips et al., 2019).

In the visual cortex, the E/I balance has been extensively investigated in MeCP2-relevant research. An early study shows that pharmacological blockade of MeCP2-mediated inhibition of GluN2B transcription enhances its expression (Lee et al., 2008), implying that GluN2B expression is likely to be increased in Mecp $2 \mathrm{KO}$ mice. Indeed, it is true in excitatory neurons of the visual cortex. The continuous GluN2B expression in pyramidal neurons disrupts normal developmental replacement of GluN2B by GluN2A (Durand et al., 2012; Mierau et al., 2016). However, in contrast to the delayed increase in the GluN2A/GluN2B ratio in excitatory neurons, the increasing ratio is instead accelerated in $\mathrm{PV}+$ interneurons in the MeCP2deficient visual cortex. This impairment is associated with vision regression, which can be reserved by early visual deprivation or genetic reduction of GluN2A in PV+ interneurons (Durand et al., 2012; Mierau et al., 2016). As opposed to NMDAR subunits, developmental modification of AMPAR composition remains unaffected in Mecp2 KO mice (Bird line). The normal expression of AMPARs may be due to developmental compensation because Mecp2 $\mathrm{KD}$ can reduce the number of AMPAR subunits GluA1 and GluA2 without affecting their accumulation in spared synapses (Blackman et al., 2012). The early increase in the GluN2A/GluN2B ratio results in an excessive innervation of $\mathrm{PV}+$ interneurons on pyramidal neurons (Durand et al., 2012). Such hyperconnectivity seems to be unique to $\mathrm{PV}+$ interneurons because transcription of the markers of other interneurons, such as calretinin and calbindin, are somewhat decreased. Furthermore, expression levels of PV and GABA synthetic enzymes glutamic acid decarboxylase 67 (GAD67) and GAD65 are increased, but the interneuron density remains unaltered (Krishnan et al., 2015). The precociousness of PV+ interneurons is consistent with the increased sIPSC amplitude observed in adjacent interneurons. Network activity was also found to be decreased. However, whether the increased inhibitory innervation among interneurons contributes to the reduced network activity remains to be determined; whether the electric coupling of interneurons is stronger is also an open question. These alterations result in an early onset of the experience-dependent critical period in the visual cortex, which can be rescued by genetically decreasing GAD67 levels (Krishnan et al., 2015). On the other hand, reduced PV expression was observed in mice with Mecp2 deletion specifically in PV+ interneurons. This downregulation was also suggested to be responsible for the alteration of an experience-dependent critical period in the visual cortex. This deficit can be restored by the pharmacological enhancement of GABAergic activity (He et al., 2014). MeCP2-deficient $\mathrm{PV}+$ interneurons exhibit increased membrane excitability but receive less excitatory input from pyramidal neurons, which results in an overall unaltered number of spontaneous spikes in $\mathrm{PV}+$ interneurons. However, a different study shows that visually-driven excitatory and inhibitory potentials in pyramidal neurons are both decreased, but to a different degree, and the overall E/I ratio is increased in Mecp2 KO mice (Bird line) (Banerjee et al., 2016). Again, these cellular alterations 
appear to be specific to $\mathrm{PV}+$ interneurons, as no or fewer effects are observed in Mecp2 deletion in SOM+ interneurons (He et al., 2014; Banerjee et al., 2016). However, it may not always be the case across the life span. A study in the visual cortex at different ages shows that although the intensity of PV immunostaining increases with age, but that of SOM and calbindin gradually decreases in Mecp2 KO mice (Bird line) (Patrizi et al., 2020).

Few studies have been focused on the auditory cortex. In female Mecp2 HET mice (Bird line), an altered inhibitory network, accompanied by increased expression of PV, can be restored by genetical reduction of GAD67 (Krishnan et al., 2017). Behaviorally, the disinhibition of deep-layer pyramidal neurons in response to maternal experience is impaired in Mecp2 HET mice (Bird line) (Lau et al., 2020a).

\section{Dysfunctional Excitation/Inhibition Balance in the Hippocampus}

An early study using cultured hippocampal neurons finds that the frequency of mEPSCs is decreased in Mecp2 KO neurons (Bird line), whereas the amplitude of mEPSCs remains unchanged (Nelson et al., 2006). However, eEPSCs are larger in amplitude in the same condition (Nelson et al., 2011). These results suggest that spontaneous and evoked neurotransmission are distinctly impacted by $\mathrm{MeCP} 2$ deficiency. In contrast, in autaptic hippocampal neurons of Mecp2 $\mathrm{KO}$ mice, the number of synapses is decreased, resulting in lower frequency of mEPSCs and smaller eEPSCs (Chao et al., 2007). Using shRNA to silence Mecp2 in hippocampal neuron cultures, a study shows fewer synaptic contacts, associated with decreased mEPSC frequency and synaptic network activity (Ma et al., 2015). It is worth noting from this study that reduced spontaneous spikes are more synchronous and $\mathrm{MeCP} 2$-deficient neurons intrinsically fire more action potentials.

In addition to neuronal cultures, acute hippocampal slices are more often utilized to test excitatory and inhibitory activity; many different results have been reported by using different mouse models. In slices prepared from symptomatic Mecp2 mice (308/Y line), which express a truncated form of MeCP2, increased excitatory synaptic transmission was observed in CA1 (Moretti et al., 2006). Voltage sensitive dye imaging in hippocampal CA1 of Mecp2 KO mice (Jaenisch line) shows enhanced peak amplitude and more spread of voltage signals, consistent with the increased slope of the input-output relationship of field EPSPs or eEPSCs (Calfa et al., 2011; Li et al., 2016). In these Mecp2 $\mathrm{KO}$ mice, the increase in amplitude and frequency of mEPSCs is shown in CA1, suggesting that both pre and postsynaptic sites are dysfunctional (Li et al., 2016). The increased postsynaptic response can be reflected by higher levels of GluA1. Consistent with the higher excitatory neuronal activity, a measurement of ambient glutamate with a fluorescence sensor expressed in pyramidal neurons discloses repetitive glutamate transients in CA1 of Mecp2 KO mice (Bird line) (Balakrishnan and Mironov, 2018a,b). In contrast to these findings, a different group did not detect altered basal neurotransmission, nor changes in levels of GluA1, GluR2, and PSD95 in Mecp2
KO mice (Jaenisch line) (Asaka et al., 2006). In hippocampal CA1 of Mecp2 (stop/y) mice, where a stop cassette is inserted to abolish MeCP2 function, recordings show normal basal synaptic transmission but are more susceptible to higher gamma frequency oscillations and epileptiform bursts in response to excitatory challenging (McLeod et al., 2013). Impairment of NMDAR-mediated activity is also likely to have a significant role in altering excitatory synaptic transmission in CA1. A report shows decreased GluN2A expression and enhanced GluN2B expression in Mecp2 KO mice (Jaenisch line) (Asaka et al., 2006). Excessive activation of extrasynaptic NMDARs is induced by abnormal $\mathrm{Ca}^{2+}$ rises in Mecp2 $\mathrm{KO}$ astrocytes (Dong et al., 2018). Regarding the inhibitory component in the E/I relationship, there seems to be no changes in the density of GABAergic interneurons, the quantity of synaptically released GABA, and the level of $\mathrm{GABA}_{A} \mathrm{R}$ expression in CA1 of Mecp2 KO mice (Jaenisch line) (Dong et al., 2020). However, CA1 shows low levels of tonic GABA resulting from enhanced activity of astrocytic GABA transporters. The reduced tonic GABA currents contribute to network hyperactivity. Besides alterations of excitation and inhibition alone, evidence also shows that reduced recurrent inhibition contributes to synaptic impairment. The decreased inhibition is due to a reduced excitatory synaptic drive onto interneurons (Lu et al., 2016). Consequently, hypersynchrony is generated, interfering with ripple oscillation-dependent memory consolidation in Mecp2 HET mice (Bird line) (Kee et al., 2018).

In hippocampal CA3 of Mecp2 KO mice (Bird line), the frequency of sEPSCs is decreased but that of sIPSPs is increased, causing a reduction in the frequency of spontaneous rhythmic field potentials (Zhang et al., 2008). However, in another study in hippocampal CA3 of Mecp2 KO mice (Jaenisch line), it was found that the amplitude of mEPSCs is enhanced while that of mIPSCs is decreased (Calfa et al., 2015). This E/I imbalance is congruent with the biochemical evidence showing higher GluA1 puncta intensity and lower intensity of $\mathrm{GABA}_{A} \mathrm{R} \alpha-1$ subunits on pyramidal neurons. The density and intrinsic property of several types of interneurons are normal, whereas the excitatory drive onto these interneurons is impaired, as reflected by smaller and less frequent mEPSCs in interneurons. In an independent study using presymptomatic Mecp2 KO mice (Bird line), the amplitude and frequency of sEPSC are increased, while those of sIPSCs are normal at birth (Lozovaya et al., 2019). However, at P15 the amplitude of sEPSCs is still high, but the frequency and amplitude of sIPSCs are reduced. Such developmental alteration of the E/I ratio accounts for synchronized population bursts in CA3. In contrast to these findings of reduced inhibitory activity in Mecp2 $\mathrm{KO}$ mice, a recent study in CA3 of presymptomatic (P30-35) and symptomatic (P50-60) mice (Bird line) did not find evident changes in $\mathrm{GABA}_{A} \mathrm{R}$-mediated activity, which suggests profound developmental compensation may occur (Belaïdouni et al., 2021).

It is certain that the E/I balance is lost in hippocampal CA1 and CA3 in Mecp2 KO mice. The dentate gyrus (DG), one of the important subregions in the hippocampus that serves as a gate for information flow, has not been studied in the context of RTT (Jedlicka et al., 2018). How the integrity of excitatory 
and inhibitory transmission is sabotaged in DG is an important subject for future investigation.

\section{Excitation/Inhibition Perturbations in the Brainstem}

Many investigations have been focused on the role of $\mathrm{E} / \mathrm{I}$ imbalance in the brainstem of MeCP2-deficient mice. An early study using in vitro heart-brainstem preparations to study breathing inspiration and expiration finds that Mecp $2 \mathrm{KO}$ mice (Bird line) exhibit irregular nerve activities, breathing arrhythmias, and apnea (Stettner et al., 2007). Injecting glutamate into the Kölliker-Fuse nucleus of the brainstem evokes a longer apnea in Mecp $2 \mathrm{KO}$ mice, suggesting a critical role of excitatory neurotransmission in regulating respiratory activity. A recent report further shows that in a rat Mecp2 KO model, excitatory activity in both nuclei responsible for inspiration and expiration is increased, which can be corrected by boosting GABAergic inhibition (Wu et al., 2021). However, the exact role of this cellular impairment in breathing abnormalities is unknown.

In the ventrolateral medullar brainstem, the amplitude and frequency of sIPSCs are decreased but those of sEPSCs are increased in Mecp2 $\mathrm{KO}$ mice (Bird line), resulting in an overturn of E/I balance (Medrihan et al., 2008). The biochemical analysis of GABAergic synapses shows that GABA content, vesicular inhibitory transmitter transporter, and postsynaptic $\mathrm{GABA}_{A} \mathrm{R}$ subunits are downregulated. Thus, treatments that increase GABA activity and decrease glutamatergic activity have been shown to ameliorate irregular breathing patterns in Mecp2 HET mice (Bird line) (Abdala et al., 2010).

The nucleus tractus solitarius (nTS) is situated in the brainstem, which conveys visceral afferent inputs to the autonomic pathway and thereby is important for the regulation of breathing. Neurons in the nTS of Mecp2 KO mice (Jaenisch line) show increased amplitudes of mEPSCs and eEPSCs and are prone to spike discharge following afferent stimuli (Kline et al., 2010). Measuring $\mathrm{GABA}_{A} \mathrm{R}$-mediated inhibitory activity in Mecp2 KO mice (Bird line) shows that the amplitude and frequency of sIPSCs are reduced in Mecp2 $\mathrm{KO}$ neurons (Chen et al., 2018). The amplitudes of mIPSCs, eIPSCs, and $\mathrm{GABA}_{A} \mathrm{R}$ agonist-induced currents are similarly decreased. Interestingly, extrasynaptic $\mathrm{GABA}_{A} \mathrm{R}$ subunits are conversely increased; however, the role of shifting inhibitory activity from synapses to extrasynapses is unknown in regulating $\mathrm{E} / \mathrm{I}$ balance.

In the hypoglossal nucleus (XII) and dorsal motor nucleus of the vagus (DMNV), inhibitory action on neurons is mediated by both GABAergic and glycinergic inputs. These inhibitory functions are both decreased in Mecp2 point mutation mice (R168X) (Xing et al., 2021), which is different from normal glycinergic activity in the ventrolateral medullar brainstem of Mecp2 KO mice (Bird line) (Medrihan et al., 2008).

In addition to those brainstem nuclei required for controlling breathing, another brainstem region, the locus coeruleus (LC) has also been investigated in MeCP2-related research. LC is the primary site for norepinephrine (NE) synthesis, involved in stress responses. In Mecp2 KO or HET mice (Jaenisch line), LC neurons are deficient in the NE-synthesizing rate-liming enzyme tyrosine hydroxylase (TH) and show hyperexcitable intrinsic properties (Taneja et al., 2009). Neuronal firing in the LC can be inhibited by $\mathrm{GABA}_{\mathrm{B}} \mathrm{R}$ - and $\mathrm{GABA}_{\mathrm{A}} \mathrm{R}$-mediated actions on pre-and postsynaptic sites, respectively. In Mecp2 KO mice (Bird line), both inhibitory mechanisms are impaired, resulting in decreased GABA release and lower activation to postsynaptic receptors (Jin et al., 2013). As in the nTS (Chen et al., 2018), extrasynaptic $\mathrm{GABA}_{A} \mathrm{R}$ subunits, including $\delta$ and $\alpha 6$, are increased in the LC (Zhong et al., 2015). The enhancement was suggested to be a compensatory reaction to the decreased GABAergic action in synapses. Pharmacological activation of these subunits can tone down the activity to a level similar to controls. In contrast to the other brain regions, it appears that the inhibitory activity was unanimously found to be decreased in the brainstem.

\section{Alterations of Excitation/Inhibition Balance in Other Brain Regions of Rett Syndrome}

Excitation/inhibition imbalance is also manifested in many other brain regions. High levels of glutamate are found in the cerebrospinal fluid of RTT patients (Hamberger et al., 1992). The amygdala receives inputs from many brain regions including the cerebral cortex (Berretta, 2005). During synaptic elimination and maturation of the early development, the amplitude of EPSCs and paired pulse ratio (PPR) decline in cortico-amygdala synapses (Gambino et al., 2010). In Mecp2 KO mice (308/Y line), the decrease ratio becomes more considerable. It remains to be addressed regarding the role of these alterations in contributing to $\mathrm{E} / \mathrm{I}$ imbalance for this particular and other inputs to the amygdala. In the visual pathway, retinal ganglion cells (RGCs) send excitatory output to the dorsal lateral geniculate nucleus (dLGN) in the thalamus. During the visual critical period, levels of MeCP2 expression are increased in excitatory synapses in the dLGN (Yagasaki et al., 2018). Dark rearing during this period results in the downregulation of MeCP2 protein. A study further shows that synaptic development is initially normal between Mecp2 KO mice (Bird line) and their controls, but AMPAR-mediated synaptic transmission becomes weaker during later development (Noutel et al., 2011). MeCP2 levels in GABAergic interneurons are stable during development (Yagasaki et al., 2018), but its exact contribution to E/I balance remains undefined.

\section{CRITICAL ELEMENTS THAT CONTRIBUTE TO EXCITATION/INHIBITION IMBALANCE IN RETT SYNDROME}

The loss of E/I balance can be caused by a direct impact of MeCP2 deficiency on the glutamatergic and GABAergic pathways. Many important elements in the brain have also been found to play profound secondary effects by influencing these excitatory and inhibitory activities. Among these elements, brain-derived neurotrophic factor (BDNF) is the most important growth factor 
that affects neurotransmission and neuronal intrinsic property. The role of BDNF has been received significant attention. I refer the reader to several past reviews (Autry and Monteggia, 2012; Katz, 2014; Li and Pozzo-Miller, 2014; Miranda-Lourenço et al., 2020). Furthermore, an inward rectifying $\mathrm{K}^{+}$channel Kir4.1 that functions to maintain normal extracellular $\mathrm{K}^{+}$levels is important for neuronal excitability (Della Vecchia et al., 2021). Expression of this channel has been found to be downregulated in Mecp2 KO mice (Jaenisch line) (Kahanovitch et al., 2018); its role has been reviewed previously (Kahanovitch et al., 2019). Here, I will highlight several other important elements that indirectly contribute to $\mathrm{E} / \mathrm{I}$ imbalance in RTT.

\section{$\mathrm{KCC}_{2} / \mathrm{NKCC}_{1}$ Ratio}

The K-Cl cotransporter isoform $2\left(\mathrm{KCC}_{2}\right)$ and $\mathrm{Na}-\mathrm{K}-2 \mathrm{Cl}$ cotransporter isoform 1 (NKCC1) are two major cation-chloride cotransporters (CCCs) in the brain, which are responsible for extruding and accumulating $\mathrm{Cl}^{-}$, respectively (Watanabe and Fukuda, 2015). Maintaining $\mathrm{Cl}^{-}$homeostasis is critical for setting the polarity and driving force of $\mathrm{GABA}_{A} \mathrm{R}$-mediated currents. The KCC2/NKCC1 ratio modification during brain development is important to switch GABAergic neurotransmission from an excitatory to an inhibitory state (Maffei et al., 2017). Abnormal alteration of the KCC2/NKCC1 ratio would alter E/I balance and contribute to RTT neuropathology (Ip et al., 2018). RTT patients have reduced KCC2/NKCC1 ratio in the cerebrospinal fluid due to lower levels of KCC2 expression (Duarte et al., 2013). Consistently, the expression of KCC2 but not NKCC1 is reduced in postmortem tissues of the RTT brain, including the cerebral cortex and hippocampus (Hinz et al., 2019). Induced pluripotent stem cells (iPSCs) from RTT patients also show a reduction in KCC2 expression and thus a delayed polarity switch (Tang et al., 2016, 2019). These studies further demonstrate that MeCP2 directly regulates KCC2 transcription and that overexpression of KCC2 restores GABAergic activity. In Mecp2 KO mouse models (Bird line), a consistent decrease in the KCC2/NKCC1 ratio was seen at different ages, which results in a positive shift of reversal potentials in pyramidal neurons (Banerjee et al., 2016; Lozovaya et al., 2019). The reduction appears to mainly occur in the frontal brain areas (Gigliucci et al., 2021). In contrast to these reports, a study in the cerebral cortex shows that KCC2 expression in adult Mecp2 Het mice (Bird line) is generally normal with high variability although it is consistently low in presymptomatic mice (Oyarzabal et al., 2020). In a small sample of RTT patients, it is even higher in brain tissues. It was suggested that KCC2 may not be directly targeted by $\mathrm{MeCP} 2$ but rather a secondary effect of neuronal activity. A more recent report also demonstrates no change in total levels of KCC2 and NKCC1 in the hippocampus but shows altered phosphorylation levels of these two channels (Belaïdouni et al., 2021). It remains to be studied if the alteration of the KCC2/NKCC1 ratio in Mecp2 KO mice is brain regionspecific and the consequence of altered phosphorylated status on inhibitory neuronal activity.

\section{Cholinergic Activity}

The cholinergic system has a crucial role in cognitive function and is affected in RTT individuals (Berger-Sweeney, 2003).
Postmortem RTT brain tissues show fewer cholinergic cells, reduced choline acetyltransferase (ChAT) activity, and decreased cholinergic receptor expression (Wenk and Mobley, 1996; Wenk, 1997; Wenk and Hauss-Wegrzyniak, 1999; Brašić et al., 2012). Mecp2 mutant animals also show reduced acetylcholine (ACh) and ChAT activity in the hippocampus, amygdala, striatum, thalamus, basal forebrain, and LC (Ricceri et al., 2011; Oginsky et al., 2014; Leung et al., 2017; Zhou et al., 2017; Murasawa et al., 2021). In Mecp2 KO mice (Bird line), currents mediated by nicotinic ACh receptors (nAChRs) are smaller in LC neurons (Oginsky et al., 2014). However, the degree of the frequency change in sIPSPs is larger in Mecp2 KO neurons during activation or inhibition of nAChRs, suggesting that nAChR modulation of GABAergic input is increased in Mecp2 KO mice. This enhanced modulation by nAChRs does not occur in glutamatergic innervations on LC neurons. It was hypothesized that the machinery of GABA release is more sensitive due to possible changes of nAChR subunit composition in Mecp2 KO interneurons. The nAChR subunits $\alpha 7$ and $\alpha 2$ have been shown to be influenced by $\mathrm{MeCP}_{2}$ deficiency (Zhang et al., 2016). Conditional deletion of Mecp2 in basal forebrain cholinergic neurons results in a decreased expression of $\alpha 7$-containing nAChRs and reduced neuronal activity in the hippocampus. This nAChR subunit is mainly expressed in PV+ interneurons. Thus, decreased nAChR activity in interneurons causes a low GABAergic inhibition and a high glutamatergic excitation due to the disinhibition. Using the same strategy to delete Mecp2 from cholinergic neurons in layers $5 / 6$ of the perirhinal cortex leads to the loss of the highly variable firing pattern characteristic of WT neurons (Ballinger et al., 2019). It is unknown how excitatory and inhibitory activities are involved in this alteration. In the cholinergic interneurons of the nucleus accumbens (NAc), deletion of Mecp2 results in reduced neuronal activity, which is mediated by the enhanced activity of $\alpha 2$-containing $\mathrm{GABA}_{A} \mathrm{Rs}$ (Zhang et al., 2020). Cholinergic modulation of glutamatergic and GABAergic neurons is clear, but its precise role in regulating E/I balance awaits additional work.

\section{Perineuronal Nets}

Perineuronal nets (PNNs) are specialized extracellular matrix responsible for the closure of the critical period for developmental plasticity (Reichelt et al., 2019). An early study indicates overexpression of PNNs in the motor cortex of RTT girls (Belichenko et al., 1997). Consistent with the precocious maturation of $\mathrm{PV}+$ interneurons, PNNs are consistently higher in Mecp2 KO mice (Bird line) during the critical period (Krishnan et al., 2015; Krishnan et al., 2017; Patrizi et al., 2020). Using super-resolution imaging to better characterize PNNs, a group finds that PV+ interneurons in the visual cortex are surrounded by more premature and higher density of PNNs in Mecp2 KO mice (Bird line) (Sigal et al., 2019). On the contrary, another study does not find increased inhibitory activity in the visual cortex and PNNs are also indistinguishable between WT and Mecp2 KO mice (Bird line) (Banerjee et al., 2016). In the CDKL5 model of an RTT variant, the density but not the percentage of PV+ interneurons surrounded by PNNs is enhanced in the visual cortex of CDKL5 KO mice, as compared with WT controls 
(Pizzo et al., 2016). Like the visual cortex, the density of PNNs in the somatosensory cortex is higher in Mecp2 HET mice (Bird line) (Lau et al., 2020b). Maternal experience induces region-specific alteration of PNNs in WT but fails to do so in Mecp2 HET mice. Elevated levels of PNNs are also seen in hippocampal CA2 of Mecp2 KO mice (Bird line), which can be downregulated via chemogenetic reduction of neuronal activity (Carstens et al., 2021). This study further demonstrates that an extracellular matrix degrading enzyme matrix metalloproteinase (MMP) is reduced in Mecp2 $\mathrm{KO}$ mice, which may explain the increased expression of PNNs.

\section{CELLULAR CONSEQUENCES OF EXCITATION/INHIBITION BALANCE}

Synaptic plasticity refers to the capacity of activity-dependent modification of synaptic strength (Citri and Malenka, 2008). To continually maintain such function, the brain is equipped with a negative feedback system for homeostatic regulation of network-wide neuronal activity (Turrigiano and Nelson, 2004). Proper glutamatergic and GABAergic synaptic transmission is foundational to establishing these two critical cellular events. I will discuss how E/I balance potentially contributes to the dysfunction of these cellular mechanisms in RTT patients and animal models.

\section{Short- and Long-Term Synaptic Plasticity}

Short-term synaptic plasticity resulting from repetitive neuronal activity acts on a timescale of tens of milliseconds to a few minutes and normally involves presynaptic mechanisms (Zucker and Regehr, 2002). Considerable efforts have been made to evaluate several classical forms of short-term plasticity in Mecp 2 mutants, including paired pulse facilitation/depression (PPF/PPD), shortterm depression (STD), and post-tetanic potentiation (PTP). An increase in the EPSP/EPSC magnitude (referred to as PPF) is mainly caused by residual $\mathrm{Ca}^{2+}$ that promotes the second response, whereas the decreased response (PPD) is generally due to inactivation of voltage-gate $\mathrm{Ca}^{2+}$ channels that inhibit transmitter release. In dissociated hippocampal neurons and acute slices, where the size of eEPSCs or field EPSPs is normally increased, $\mathrm{PPF}$ is decreased in MeCP2-deficient groups (Moretti et al., 2006; Nelson et al., 2006; Calfa et al., 2011; Nelson et al., 2011; Li et al., 2016). However, the decrease is also seen in synapses, where basal neurotransmission is normal (Asaka et al., 2006; Weng et al., 2011) or decreased (Gambino et al., 2010). Similarly, STD that typically reflects the depletion rate of readily releasable vesicles is also decreased during $10-\mathrm{Hz}$ stimulation in Mecp2 mutants (Nelson et al., 2006). In contrast to alterations of the fast action of presynaptic function, the relatively slow presynaptic activity that involves mobilization of the reserve pool of synaptic vesicles appears unaffected, as evidenced in unchanged PTP induced by high frequency stimuli (Asaka et al., 2006; Guy et al., 2007). These presynaptic measures appear to be normal in some models. For instance, intracellular whole-cell recordings revealed that PPF and/or STD are not affected by $M e c p 2$ deletion in autaptic hippocampal neurons and neocortical layer 5 pyramidal neurons (Chao et al., 2007; Dani and Nelson, 2009).

Long-term synaptic plasticity including long-term potentiation (LTP) and depression (LTD) has become a powerful parameter for understanding the neurobiological basis of RTT. MeCP2 deficiency in symptomatic mice results in impairments in LTP and LTD in hippocampal CA3-CA1 synapses (Jaenisch line) (Asaka et al., 2006). The impaired LTP and neurological abnormalities in Mecp2 mutant mice can be reversed following Mecp2 reactivation by genetic manipulation (Guy et al., 2007). Mechanistically, LTP defect has been associated with abnormally enhanced AMPAR-mediated synaptic transmission (Moretti et al., 2006). LTP defect is also shown in synapses with increased NMDAR activity; partial blockade by memantine restores the early phase of LTP (Weng et al., 2011). LTP in hippocampal CA1 generally requires AMPAR trafficking into the postsynaptic site (Diering and Huganir, 2018). In hippocampal CA1 of Mecp2 KO mice (Jaenisch line) with higher synaptic transmission, LTP is occluded in these potentiated synapses because they fail to insert AMPARs into the membrane (Li et al., 2016). It should be noted that LTP defect may also be attributable to the reduced number of synapses. Paired recordings in cortical layer 5 pyramidal neuron of Mecp2 KO mice (Jaenisch line) demonstrate LTP deficit, which can be restored when postsynaptic neurons are given sufficient depolarization to overcome weak connection (Dani and Nelson, 2009). It is also the case for cortico-lateral amygdala synapses where LTP is intact after paring pre- with postsynaptic activities (Gambino et al., 2010). Apart from glutamatergic activity, the role of proper GABAergic function is also important for synaptic plasticity. A report shows that LTP is impaired in a mouse model deficient of MeCP2 specifically in GABAergic interneurons (Chao et al., 2010). The impairment of LTP-like plasticity is also shown in the motor cortex of RTT patients, which favors cortical hyperexcitation as a result of GABAergic dysfunction (Bernardo et al., 2020). LTP in hippocampal CA2 of Mecp2 KO mice (Bird line) is disrupted due to enhanced expression of PNNs and can be rescued by degrading PNNs (Carstens et al., 2021). LTD is also affected in CA3 pyramidal neurons of Mecp2 KO mice (Bird line) because of the loss of developmental shift of GABAergic activity (Lozovaya et al., 2019). These findings indicate that maintaining E/I balance is critical for the induction of synaptic plasticity.

\section{Homeostatic Synaptic Plasticity}

Homeostatic synaptic plasticity is accomplished by adjusting neuronal intrinsic or synaptic properties. Synaptic scaling up and down, two of the best-characterized forms of homeostatic plasticity, have been recently used in dissociated cultures or slices to determine the role of MeCP2. Synaptic scaling down during the bicuculline treatment is impaired in Mecp2lacking hippocampal neurons (Qiu et al., 2012). In wildtype neurons, scaling down is mechanistically associated with MeCP2 upregulation and GluA2 receptor downregulation. Using a mouse model with Mecp2 phosphate mutation at S421 and S424, a study further indicates that phosphorylation at these two loci is necessary for synaptic scaling down but not up (Zhong et al., 2012). This modification is mediated by metabotropic 
glutamate receptor 5 (mGluR5). Research on CNQX-eliciting scaling up demonstrates a loss of GluA1-mediated enhancement of spontaneous synaptic transmission in pyramidal neurons deficient in MeCP2 (Blackman et al., 2012). Furthermore, increased synaptic activity induced by visual deprivation is disrupted in Mecp2 $\mathrm{KO}$ mice, which provides in vivo evidence for the role of MeCP2 in synaptic scaling up.

In a more comprehensive study, by monitoring GluA1 trafficking in and out of membrane, both scaling up and down were found to be impaired in Mecp2 $\mathrm{KO}$ neurons treated with TTX and bicuculine, respectively. Early endosome antigen 1 (EEA1), a protein involved in GluA1 endocytosis, is lower in Mecp2 KO mice (Jaenisch line) (Xu and Pozzo-Miller, 2017). Expression of EEA1 in Mecp2 KO mice reduces the amplitude of mEPSCs and at the same time restores synaptic scaling down. These findings suggest that Mecp 2 has a role in maintaining both normal synaptic transmission and synaptic scaling, but future investigation is needed to explore shared mechanisms and the interplay between them.

\section{Pharmacological Treatments That Improve Excitation/Inhibition Balance}

As E/I balance is of paramount importance in many brain events, restoration of E/I balance should be the aim for designing any treatments. In the last several decades, many genetic, pharmacological, and physiological treatments have been tested in individuals with RTT or mouse models, but few were assessed in the context of E/I balance. Here, I will discuss some pharmacological interventions for RTT and their potential impact on excitatory and/or inhibitory activities.

\section{Glutamatergic Modulators}

In those brain regions where excitatory synaptic transmission is decreased, boosting AMPAR-mediated activity is likely to be beneficial. AMPAkines, positive allosteric AMPAR modulators, are known to increase the size of AMPAR-mediated excitatory synaptic responses and enhance BDNF expression (Lynch and Gall, 2006). Chronic treatment with the AMPAkine CX546 restores normal breathing patterns in Mecp2 KO mice (Jaenisch line) (Ogier et al., 2007).

The role of NMDAR dysfunction in RTT has been evident in multiple brain regions (Blue et al., 1999, 2011; Durand et al., 2012; Nguyen et al., 2012; Mierau et al., 2016). Ketamine, an NMDAR antagonist, is known to enhance neuronal activity in the forebrain by disinhibiting cortical pyramidal neurons (Jackson et al., 2004). In the hypoactive forebrain of Mecp2 $\mathrm{KO}$ mice (Jaenisch line), a sub-psychotomimetic dose of ketamine is able to restore neuronal activity and sensorimotor gating activity (Kron et al., 2012). In the visual cortex of Mecp $2 \mathrm{KO}$ mice (Bird line), premature enhancement of GluN2A/GluN2B can also be inhibited by ketamine, leading to a delay of visual regression (Patrizi et al., 2016). However, since RTT brains demonstrate a mixture of hypo- and hyperactivity, the effect of ketamine on those neural circuits with higher activity is unknown. Furthermore, in the CDKL5 KO mouse model of atypic RTT, the enhanced expression of GluN2B in the hippocampus accounts for seizures (Okuda et al., 2017). Treatment with the GluN2B-selective antagonist ifenprodil is capable of inhibiting epileptic activity.

In addition to these ionotropic glutamate receptors, metabotropic glutamate receptors (mGlu) are also affected in RTT. Postsynaptic mGlu5 is reduced in RTT patients and MeCP2-deficient mice (Bird line) (Gogliotti et al., 2016). Treatment with a mGlu5 modulator VU0462807 restores normal synaptic plasticity, motor behaviors, and other general phenotypes. The activation of presynaptic mGlu7 on interneurons is required for LTP in the hippocampal CA3CA1 synapses (Klar et al., 2015). Its expression level is also low in RTT patients and mice (Gogliotti et al., 2017). Modulation of mGlu7 by VU0422288 leads to the restoration of respiratory, learning, and social deficits.

\section{GABAergic Modulators}

Pharmacological modulation of GABAergic activity has shown to be effective in recovering cellular, network, behavioral dysfunction in RTT patients and mice (Braat and Kooy, 2015). In primary hippocampal neurons, Mecp2 KD results in a decrease in the frequency of mEPSCs and an impairment in network activity, both of which can be reversed by a $\mathrm{GABA}_{A} \mathrm{R}$ modulator pentobarbital (Ma et al., 2015). In the respiratory center of the brainstem, the E/I ratio is generally increased. Enhancing GABAergic activity by the GABA reuptake blocker NO-711 or the $\mathrm{GABA}_{A} \mathrm{R}$ modulators benzodiazepines, produces a reduction of the number of apneas and an improvement in breathing rhythm in Mecp2 KO mice (Bird line) (Abdala et al., 2010; Voituron and Hilaire, 2011). Administration of the GABAergic reuptake inhibitor tiagabine to Mecp2 KO mice (Bird line) extends the life span (El-Khoury et al., 2014). In addition to synaptic $\mathrm{GABA}_{A}$ Rs, activation of extrasynaptic $\mathrm{GABA}_{A}$ Rs by THIP also rescues these abnormalities (Zhong et al., 2016). To avoid an excessive inhibition of the hypoactive forebrain, cloperastine that preferentially targets the brainstem was used to treat Mecp2 KO mice (R168X line) (Johnson et al., 2020). It markedly decreases the occurrence of breathing irregulates. Mechanistically, it mainly excites GABAergic interneurons via blockade of Kir channel activity.

\section{Brain-Derived Neurotrophic Factor Mimetics}

Brain-derived neurotrophic factor is a neurotrophic factor and has a profound role in modulating neurotransmission and plasticity of excitatory and inhibitory synapses (Schuman, 1999). BDNF levels are reduced in the entire brain of Mecp2 $\mathrm{KO}$ mice (Jaenisch line) (Chang et al., 2006; Li et al., 2012); augmenting the BDNF signaling is a promising avenue to treat RTT (Li and Pozzo-Miller, 2014). Acute BDNF treatment reverses neuronal hyperexcitability in the brainstem nTS (Kline et al., 2010). To overcome its limited ability in crossing the blood-brain barrier, two BDNF mimetics LM22A-A and PTXBD4-3 have been developed, which have a high penetration rate and selectively activate BDNF downstream signaling. Administration of LM22A-4 or PTX-BD4-3 to Mecp2 HET mice (Jaenisch line) restores normal respiratory frequency, motor 
activity, and object location memory (Schmid et al., 2012; Li et al., 2017; Adams et al., 2020). Behavioral recovery is associated with the decrease of the hyperactive network and the reduction of the oversaturated excitatory synaptic transmission. Fingolimod, another BDNF mimetic that can stimulate BDNF expression, ameliorates symptoms in Mecp2 KO mice (Bird line) (Deogracias et al., 2012), although its effectiveness in treating RTT patients was recently shown to be limited (Naegelin et al., 2021). A BDNF receptor activator 7,8-dihydroxyflavone was also reported to extend the life span and improve locomotor activity and breathing issues in Mecp2 $\mathrm{KO}$ mice (Jaenisch line) (Johnson et al., 2012).

\section{Antidepressants}

Many antidepressants have been used to treat RTT (Persico et al., 2019). Desipramine that functions to inhibit norepinephrine reuptake improves breathing rhythm and prolongs life span in Mecp2 KO mice (Roux et al., 2007; Zanella et al., 2008). Mirtazapine, a more tolerable noradrenergic antidepressant also ameliorates motor and social behaviors in RTT patients and Mecp2 KO mice (Bird line) (Bittolo et al., 2016; Flores Gutiérrez et al., 2020). Examination of pyramidal neurons in the somatosensory cortex reveals that mirtazapine restores neuronal dendritic arborization and spine density and improves glutamatergic and GABAergic activity in Mecp2 $\mathrm{KO}$ mice. Fluoxetine, a serotonin reuptake inhibitor, can rescue motor abnormality by increasing the number of $\mathrm{MeCP} 2+$ cells in Mecp2 HET mice (Bird line) (Villani et al., 2020, 2021). The molecular mechanisms underlying antidepressant treatments have been related to BDNF expression and phosphorylation of MeCP2. Chronic treatment with several major classes of antidepressants increases BDNF levels (Nibuya et al., 1995; Altar et al., 2003). Imipramine, an inhibitor of the serotonin and norepinephrine transporters, induces phosphorylation of MeCP2 at Ser421 (Hutchinson et al., 2012). The effect of antidepressant fluoxetine involves releasing $\mathrm{MeCP} 2$ from binding to $b d n f$ promoter and enhancing BDNF expression (Jin et al., 2017). A recent study also shows an inverse relationship in which the effect of antidepressants is associated with phosphorylation of MeCP2 by released BDNF (Kim et al., 2021). Clearly, these antidepressants affect both excitatory and inhibitory neurotransmission, but their detailed role in modifying E/I balance remains to be discovered.

\section{Insulin-Like Growth Factor-1}

Insulin-like growth factor-1, a neurotrophic factor, is critical for neuronal maturation and survival by activating PI3K-AKTmTOR and MAPK-ERK pathways (Riikonen, 2016). Expression of IGF-1 and its downstream signals is downregulated in Mecp2 $\mathrm{KO}$ and HET models (Jaenisch and Bird lines) (Ricciardi et al., 2011; Castro et al., 2014). Administration of IGF-1 peptide or recombinant full-length human IGF-1 (rhIGF-1) to RTT patients and mouse models has been shown to improve some symptoms and prolong life span, although its effectiveness is variable (Tropea et al., 2009; Castro et al., 2014; Khwaja et al., 2014; Pini et al., 2016; O’Leary et al., 2018; Yuan et al., 2020). Treatment with IGF-1 increases the amplitude of eEPSCs and the levels of PSD-95 in Mecp2 KO mice (Bird line) (Tropea et al., 2009; Castro et al., 2014) or CDKL5 KO mice (Della Sala et al., 2016). RTT patients' iPSCs exhibit a low density of excitatory synapses and short neurite length, which can be normalized by IGF-1 treatment (Marchetto et al., 2010; de Souza et al., 2016). IGF-1 also improves network connectivity in MeCP2-deficient hippocampal neurons (Sun et al., 2018). Furthermore, IGF-1 or rhIGF-1 promotes the KCC2/NKCC1 ratio in the visual cortex (Banerjee et al., 2016; Gigliucci et al., 2021). These effects are beneficial to the improvement of the $\mathrm{E} / \mathrm{I}$ balance.

\section{Histone Deacetylase 6 (HDAC6) Inhibitors}

Histone deacetylase 6, a microtubule-associated enzyme, plays a negative role in cell migration and vesicle transport by regulating acetylation of $\alpha$-tubulin (Hubbert et al., 2002). Increased levels of HDAC6 have been found in MeCP2-deficient cells, indicating the disturbance of microtubule dynamics (Delépine et al., 2015; Gold et al., 2015). An HDAC-6 inhibitor, tubastatin-A can correct microtubule defects and reverse impaired exploratory activity in Mecp2 KO mice (308/Y line) (Lebrun et al., 2021). The treatment also enhances BDNF anterograde and retrograde transport and release (Xu and Pozzo-Miller, 2017), therefore allowing secreted BDNF to improve the E/I ratio. However, another study shows that inhibition of HDAC by a non-selective inhibitor, in turn, reduces the frequency of mEPSCs in control neurons to a level similar as seen in Mecp2 KO neurons (Bird line) (Nelson et al., 2006). The exact mechanisms by which HDAC affects neuron activity need to be investigated.

\section{Mitochondria Targeting Drugs}

Bacterial cytotoxic necrotizing factor 1 (CNF1) activates intracellular Rho-GTPases and protects mitochondria from the production of reactive oxygen species (ROS) (Travaglione et al., 2014; De Filippis et al., 2015b; Fabbri et al., 2018). Through these effects, CNF1 modulates actin cytoskeleton dynamics and enhances synaptic transmission and plasticity (Amir et al., 1999; Diana et al., 2007). Mecp2 KO and HET mice treated with CNF1 show a significant improvement in cognition and motor function (308/Y and Bird line) (De Filippis et al., 2012; Urbinati et al., 2021). CNF1 treatment also prevents an enhancement of GluN2B-tyrosine phosphorylation and facilitates LTP induction in hippocampal CA1 of Mecp2 HET mice. These findings imply that CNF-1 can promote E/I balance (De Filippis et al., 2015a).

Vitamin $\mathrm{E}$ is an important antioxidant that prevents oxidative damage by scavenging ROS (Lee and Han, 2018). Serum levels of vitamin E are lower in RTT patients (Formichi et al., 1998). Hippocampal slices treated with the vitamin E derivative, Trolox, show the dampening of hyperactive synaptic transmission and the improvement of short- and long-term synaptic plasticity (Janc and Müller, 2014). Systemic Trolox administration also ameliorates some synaptic and behavioral phenotypes in Mecp2 KO mice (Bird line) (Janc et al., 2016). CoQ10 is a substance 
that also can attenuate ROS in RTT patients; however, its effect has not yet been determined (Di Pierro et al., 2020).

\section{CONCLUDING REMARKS}

The E/I imbalance certainly is a hub of RTT pathogenesis, which manifests the outcome of genetic and molecular perturbations and underlies the progression trajectories of neurologic signs. Our understanding of E/I imbalance in RTT has made a great deal of progress. However, the evidence that we currently possess is mainly derived from assessments on either an excitatory or inhibitory side. In other words, we have not yet confidently explicated the role of $\mathrm{E} / \mathrm{I}$ imbalance in an entire synaptic and circuit realm, nor fully elucidate the relevance of the loss of E/I stability in RTT symptoms and evaluate all potential therapies on the basis of the E/I outcome. With the increasing endeavors devoted to addressing the role of E/I imbalance in RTT, we hope that the scientific knowledge gleaned from these studies will be translated into effective therapies available for RTT and

\section{REFERENCES}

Abdala, A. P., Dutschmann, M., Bissonnette, J. M., and Paton, J. F. (2010). Correction of respiratory disorders in a mouse model of Rett syndrome. Proc. Natl. Acad. Sci. U.S.A. 107, 18208-18213. doi: 10.1073/pnas.1012104107

Adams, I., Yang, T., Longo, F. M., and Katz, D. M. (2020). Restoration of motor learning in a mouse model of Rett syndrome following long-term treatment with a novel small-molecule activator of TrkB. Dis. Models Mech. 13:dmm044685. doi: 10.1242/dmm.044685

Altar, C. A., Whitehead, R. E., Chen, R., Wörtwein, G., and Madsen, T. M. (2003). Effects of electroconvulsive seizures and antidepressant drugs on brain-derived neurotrophic factor protein in rat brain. Biol. Psychiatry 54, 703-709. doi: 10.1016/s0006-3223(03)00073-8

Amir, R. E., Van den Veyver, I. B., Wan, M., Tran, C. Q., Francke, U., and Zoghbi, H. Y. (1999). Rett syndrome is caused by mutations in X-linked MECP2, encoding methyl-CpG-binding protein 2. Nat. Genet. 23, 185-188. doi: 10.1038/ 13810

Armstrong, D. D. (2005). Neuropathology of Rett syndrome. J. Child Neurol. 20, 747-753. doi: 10.1177/08830738050200090901

Asaka, Y., Jugloff, D. G., Zhang, L., Eubanks, J. H., and Fitzsimonds, R. M. (2006). Hippocampal synaptic plasticity is impaired in the Mecp2-null mouse model of Rett syndrome. Neurobiol. Dis. 21, 217-227. doi: 10.1016/j.nbd.2005.07.005

Autry, A. E., and Monteggia, L. M. (2012). Brain-derived neurotrophic factor and neuropsychiatric disorders. Pharmacol. Rev. 64, 238-258. doi: 10.1124/pr.111. 005108

Balakrishnan, S., and Mironov, S. L. (2018a). CA1 neurons acquire rett syndrome phenotype after brief activation of glutamatergic receptors: specific role of mGluR1/5. Front. Cell. Neurosci. 12:363. doi: 10.3389/fncel.2018.0 0363

Balakrishnan, S., and Mironov, S. L. (2018b). Regenerative glutamate release in the hippocampus of Rett syndrome model mice. PLoS One 13:e0202802. doi: 10.1371/journal.pone.0202802

Ballinger, E. C., Schaaf, C. P., Patel, A. J., de Maio, A., Tao, H., Talmage, D. A., et al. (2019). Mecp2 deletion from cholinergic neurons selectively impairs recognition memory and disrupts cholinergic modulation of the perirhinal cortex. eNeuro 6, 1-13. doi: 10.1523/eneuro.0134-19.2019

Banerjee, A., Rikhye, R. V., Breton-Provencher, V., Tang, X., Li, C., Li, K., et al. (2016). Jointly reduced inhibition and excitation underlies circuit-wide changes in cortical processing in Rett syndrome. Proc. Natl. Acad. Sci. U.S.A. 113, E7287-E7296. doi: 10.1073/pnas.1615330113 other neurological and psychiatric diseases that share similar neuropathological substrates.

\section{AUTHOR CONTRIBUTIONS}

WL wrote and edited the manuscript and approved the submitted version.

\section{FUNDING}

Funding was provided by grants from NIH (NS121542, NS120315, NS108508, and NS097913).

\section{ACKNOWLEDGMENTS}

I am grateful to Lucas Pozzo-Miller and Destynie Medeiros for discussions and comments on the manuscript. I thank Xin $\mathrm{Xu}$ and Cesar Acevedo for discussions.

Belaïdouni, Y., Diabira, D., Zhang, J., Graziano, J. C., Bader, F., Montheil, A., et al. (2021). The chloride homeostasis of CA3 hippocampal neurons is not altered in fully symptomatic Mepc2-null mice. Front. Cell. Neurosci. 15:724976. doi: 10.3389/fncel.2021.724976

Belichenko, P. V., Hagberg, B., and Dahlström, A. (1997). Morphological study of neocortical areas in rett syndrome. Acta Neuropathol. 93, 50-61. doi: 10.1007/ s004010050582

Berger-Sweeney, J. (2003). The cholinergic basal forebrain system during development and its influence on cognitive processes: important questions and potential answers. Neurosci. Biobehav. Rev. 27, 401-411. doi: 10.1016/s01497634(03)00070-8

Bernardo, P., Cobb, S., Coppola, A., Tomasevic, L., Di Lazzaro, V., Bravaccio, C., et al. (2020). Neurophysiological signatures of motor impairment in patients with rett syndrome. Ann. Neurol. 87, 763-773. doi: 10.1002/ana.25712

Berretta, S. (2005). Cortico-amygdala circuits: role in the conditioned stress response. Stress 8, 221-232. doi: 10.1080/10253890500489395

Bittolo, T., Raminelli, C. A., Deiana, C., Baj, G., Vaghi, V., Ferrazzo, S., et al. (2016). Pharmacological treatment with mirtazapine rescues cortical atrophy and respiratory deficits in MeCP2 null mice. Sci. Rep. 6:19796. doi: 10.1038/ srep 19796

Blackman, M. P., Djukic, B., Nelson, S. B., and Turrigiano, G. G. (2012). A critical and cell-autonomous role for MeCP2 in synaptic scaling up. J. Neurosci. 32, 13529-13536. doi: 10.1523/jneurosci.3077-12.2012

Blue, M. E., Kaufmann, W. E., Bressler, J., Eyring, C., O’Driscoll, C., Naidu, S., et al. (2011). Temporal and regional alterations in NMDA receptor expression in Mecp2-null mice. Anat. Rec. (Hoboken) 294, 1624-1634. doi: 10.1002/ar.21380

Blue, M. E., Naidu, S., and Johnston, M. V. (1999). Development of amino acid receptors in frontal cortex from girls with Rett syndrome. Ann. Neurol. 45, 541-545. doi: 10.1002/1531-8249(199904)45:4\&lt;541::aid-ana21\&gt;3. $0 . \mathrm{co} ; 2-2$

Braat, S., and Kooy, R. F. (2015). The GABAA receptor as a therapeutic target for neurodevelopmental disorders. Neuron 86, 1119-1130. doi: 10.1016/j.neuron. 2015.03.042

Brašić, J. R., Bibat, G., Kumar, A., Zhou, Y., Hilton, J., Yablonski, M. E., et al. (2012). Correlation of the vesicular acetylcholine transporter densities in the striata to the clinical abilities of women with Rett syndrome. Synapse 66, 471-482. doi: 10.1002/syn.21515

Calfa, G., Hablitz, J. J., and Pozzo-Miller, L. (2011). Network hyperexcitability in hippocampal slices from Mecp 2 mutant mice revealed by voltage-sensitive dye imaging. J. Neurophysiol. 105, 1768-1784. doi: 10.1152/jn.00800.2010 
Calfa, G., Li, W., Rutherford, J. M., and Pozzo-Miller, L. (2015). Excitation/inhibition imbalance and impaired synaptic inhibition in hippocampal area CA3 of Mecp2 knockout mice. Hippocampus 25, 159-168. doi: 10.1002/hipo.22360

Carstens, K. E., Lustberg, D. J., Shaughnessy, E. K., McCann, K. E., Alexander, G. M., and Dudek, S. M. (2021). Perineuronal net degradation rescues CA2 plasticity in a mouse model of Rett syndrome. J. Clin. Invest. 131:e137221. doi: $10.1172 /$ jci137221

Castro, J., Garcia, R. I., Kwok, S., Banerjee, A., Petravicz, J., Woodson, J., et al. (2014). Functional recovery with recombinant human IGF1 treatment in a mouse model of Rett Syndrome. Proc. Natl. Acad. Sci. U.S.A. 111, 9941-9946. doi: $10.1073 /$ pnas.1311685111

Chahrour, M., and Zoghbi, H. Y. (2007). The story of Rett syndrome: from clinic to neurobiology. Neuron 56, 422-437. doi: 10.1016/j.neuron.2007.10.001

Chang, Q., Khare, G., Dani, V., Nelson, S., and Jaenisch, R. (2006). The disease progression of Mecp2 mutant mice is affected by the level of BDNF expression. Neuron 49, 341-348. doi: 10.1016/j.neuron.2005.12.027

Chao, H. T., Zoghbi, H. Y., and Rosenmund, C. (2007). MeCP2 controls excitatory synaptic strength by regulating glutamatergic synapse number. Neuron 56 , 58-65. doi: 10.1016/j.neuron.2007.08.018

Chao, H.-T., Chen, H., Samaco, R. C., Xue, M., Chahrour, M., Yoo, J., et al. (2010). Dysfunction in GABA signalling mediates autism-like stereotypies and Rett syndrome phenotypes. Nature 468, 263-269. doi: 10.1038/nature09582

Chen, C. Y., Di Lucente, J., Lin, Y. C., Lien, C. C., Rogawski, M. A., Maezawa, I., et al. (2018). Defective GABAergic neurotransmission in the nucleus tractus solitarius in Mecp2-null mice, a model of Rett syndrome. Neurobiol. Dis. 109(Pt. A), 25-32. doi: 10.1016/j.nbd.2017.09.006

Chen, L., Chen, K., Lavery, L. A., Baker, S. A., Shaw, C. A., Li, W., et al. (2015). $\mathrm{MeCP} 2$ binds to non-CG methylated DNA as neurons mature, influencing transcription and the timing of onset for Rett syndrome. Proc. Natl. Acad. Sci. U.S.A. 112, 5509-5514. doi: 10.1073/pnas.1505909112

Cheval, H., Guy, J., Merusi, C., De Sousa, D., Selfridge, J., and Bird, A. (2012). Postnatal inactivation reveals enhanced requirement for $\mathrm{MeCP} 2$ at distinct age windows. Hum. Mol. Genet. 21, 3806-3814. doi: 10.1093/hmg/dds208

Citri, A., and Malenka, R. C. (2008). Synaptic plasticity: multiple forms, functions, and mechanisms. Neuropsychopharmacology 33, 18-41. doi: 10.1038/sj.npp. 1301559

Dani, V. S., and Nelson, S. B. (2009). Intact long-term potentiation but reduced connectivity between neocortical layer 5 pyramidal neurons in a mouse model of Rett syndrome. J. Neurosci. 29, 11263-11270. doi: 10.1523/jneurosci.101909.2009

Dani, V. S., Chang, Q., Maffei, A., Turrigiano, G. G., Jaenisch, R., and Nelson, S. B. (2005). Reduced cortical activity due to a shift in the balance between excitation and inhibition in a mouse model of Rett Syndrome. Proc. Natl. Acad. Sci. U.S.A. 102, 12560-12565. doi: 10.1073/pnas.0506071102

De Filippis, B., Fabbri, A., Simone, D., Canese, R., Ricceri, L., Malchiodi-Albedi, F., et al. (2012). Modulation of RhoGTPases improves the behavioral phenotype and reverses astrocytic deficits in a mouse model of Rett syndrome. Neuropsychopharmacology 37, 1152-1163. doi: 10.1038/npp. 2011.301

De Filippis, B., Valenti, D., de Bari, L., De Rasmo, D., Musto, M., Fabbri, A., et al. (2015b). Mitochondrial free radical overproduction due to respiratory chain impairment in the brain of a mouse model of Rett syndrome: protective effect of CNF1. Free Radic. Biol. Med. 83, 167-177. doi: 10.1016/j.freeradbiomed.2015. 02.014

De Filippis, B., Valenti, D., Chiodi, V., Ferrante, A., de Bari, L., Fiorentini, C., et al. (2015a). Modulation of Rho GTPases rescues brain mitochondrial dysfunction, cognitive deficits and aberrant synaptic plasticity in female mice modeling Rett syndrome. Eur. Neuropsychopharmacol. 25, 889-901. doi: 10.1016/j.euroneuro. 2015.03.012

de Souza, J. S., Carromeu, C., Torres, L. B., Araujo, B. H. S., Cugola, F. R., Maciel, R. M. B., et al. (2016). IGF1 neuronal response in the absence of MECP2 is dependent on TRalpha 3. Hum. Mol. Genet. 26, 270-281. doi: 10.1093/hmg/ ddw384

Delépine, C., Meziane, H., Nectoux, J., Opitz, M., Smith, A. B., Ballatore, C., et al. (2015). Altered microtubule dynamics and vesicular transport in mouse and human MeCP2-deficient astrocytes. Hum. Mol. Genet. 25, 146-157. doi: $10.1093 / \mathrm{hmg} / \mathrm{ddv} 464$
Della Sala, G., Putignano, E., Chelini, G., Melani, R., Calcagno, E., Michele Ratto, G., et al. (2016). Dendritic spine instability in a mouse model of CDKL5 disorder is rescued by insulin-like growth factor 1. Biol. Psychiatry 80, 302-311. doi: 10.1016/j.biopsych.2015.08.028

Della Vecchia, S., Marchese, M., Santorelli, F. M., and Sicca, F. (2021). Kir4.1 dysfunction in the pathophysiology of depression: a systematic review. Cells 10:2628. doi: 10.3390/cells10102628

Deogracias, R., Yazdani, M., Dekkers, M. P., Guy, J., Ionescu, M. C., Vogt, K. E., et al. (2012). Fingolimod, a sphingosine-1 phosphate receptor modulator, increases BDNF levels and improves symptoms of a mouse model of Rett syndrome. Proc. Natl. Acad. Sci. U.S.A. 109, 14230-14235. doi: 10.1073/pnas. 1206093109

Di Pierro, D., Ciaccio, C., Sbardella, D., Tundo, G. R., Bernardini, R., Curatolo, P., et al. (2020). Effects of oral administration of common antioxidant supplements on the energy metabolism of red blood cells. Attenuation of oxidative stressinduced changes in Rett syndrome erythrocytes by CoQ10. Mol. Cell. Biochem. 463, 101-113. doi: 10.1007/s11010-019-03633-5

Diana, G., Valentini, G., Travaglione, S., Falzano, L., Pieri, M., Zona, C., et al. (2007). Enhancement of learning and memory after activation of cerebral Rho GTPases. Proc. Natl. Acad. Sci. U.S.A. 104, 636-641. doi: 10.1073/pnas. 0610059104

Diering, G. H., and Huganir, R. L. (2018). The AMPA receptor code of synaptic plasticity. Neuron 100, 314-329. doi: 10.1016/j.neuron.2018.10.018

Dong, Q., Kim, J., Nguyen, L., Bu, Q., and Chang, Q. (2020). An astrocytic influence on impaired tonic inhibition in hippocampal CA1 pyramidal neurons in a mouse model of rett syndrome. J. Neurosci. 40, 6250-6261. doi: 10.1523/ jneurosci.3042-19.2020

Dong, Q., Liu, Q., Li, R., Wang, A., Bu, Q., Wang, K. H., et al. (2018). Mechanism and consequence of abnormal calcium homeostasis in Rett syndrome astrocytes. Elife 7:e33417. doi: 10.7554/eLife.33417

Duarte, S. T., Armstrong, J., Roche, A., Ortez, C., Pérez, A., O'Callaghan Mdel, M., et al. (2013). Abnormal expression of cerebrospinal fluid cation chloride cotransporters in patients with Rett syndrome. PLoS One 8:e68851. doi: 10. 1371/journal.pone.0068851

Durand, S., Patrizi, A., Quast, K. B., Hachigian, L., Pavlyuk, R., Saxena, A., et al. (2012). NMDA receptor regulation prevents regression of visual cortical function in the absence of Mecp2. Neuron 76, 1078-1090. doi: 10.1016/j.neuron. 2012.12.004

Einspieler, C., Kerr, A. M., and Prechtl, H. F. (2005). Is the early development of girls with Rett disorder really normal? Pediatr. Res. 57(5 Pt. 1), 696-700. doi: 10.1203/01.Pdr.0000155945.94249.0a

El-Khoury, R., Panayotis, N., Matagne, V., Ghata, A., Villard, L., and Roux, J. C. (2014). GABA and glutamate pathways are spatially and developmentally affected in the brain of Mecp2-deficient mice. PLoS One 9:e92169. doi: 10.1371/ journal.pone.0092169

Eyre, J. A., Kerr, A. M., Miller, S., O'Sullivan, M. C., and Ramesh, V. (1990). Neurophysiological observations on corticospinal projections to the upper limb in subjects with Rett syndrome. J. Neurol. Neurosurg. Psychiatry 53, 874-879. doi: 10.1136/jnnp.53.10.874

Fabbri, A., Travaglione, S., Maroccia, Z., Guidotti, M., Pierri, C. L., Primiano, G., et al. (2018). The bacterial protein CNF1 as a potential therapeutic strategy against mitochondrial diseases: a pilot study. Int. J. Mol. Sci. 19:1825. doi: 10.3390/ijms 19071825

Flores Gutiérrez, J., De Felice, C., Natali, G., Leoncini, S., Signorini, C., Hayek, J., et al. (2020). Protective role of mirtazapine in adult female Mecp2(+/-) mice and patients with Rett syndrome. J. Neurodev. Disord. 12:26. doi: 10.1186/s11689020-09328-z

Formichi, P., Battisti, C., Dotti, M. T., Hayek, G., Zappella, M., and Federico, A. (1998). Vitamin E serum levels in Rett syndrome. J. Neurol. Sci. 156, 227-230. doi: 10.1016/s0022-510x(98)00035-5

Gambino, F., Khelfaoui, M., Poulain, B., Bienvenu, T., Chelly, J., and Humeau, Y. (2010). Synaptic maturation at cortical projections to the lateral amygdala in a mouse model of Rett syndrome. PLoS One 5:e11399. doi: 10.1371/journal.pone. 0011399

Gigliucci, V., Teutsch, J., Woodbury-Smith, M., Luoni, M., Busnelli, M., Chini, B., et al. (2021). Region-Specific KCC2 rescue by rhIGF-1 and oxytocin in a mouse model of rett syndrome. Cereb. Cortex bhab388. doi: 10.1093/cercor/bhab388 [Epub ahead of print]. 
Gogliotti, R. G., Senter, R. K., Fisher, N. M., Adams, J., Zamorano, R., Walker, A. G., et al. (2017). mGlu(7) potentiation rescues cognitive, social, and respiratory phenotypes in a mouse model of Rett syndrome. Sci. Transl. Med. 9:eaai7459. doi: 10.1126/scitranslmed.aai7459

Gogliotti, R. G., Senter, R. K., Rook, J. M., Ghoshal, A., Zamorano, R., Malosh, C., et al. (2016). mGlu5 positive allosteric modulation normalizes synaptic plasticity defects and motor phenotypes in a mouse model of Rett syndrome. Hum. Mol. Genet. 25, 1990-2004. doi: 10.1093/hmg/ddw074

Gold, W. A., Lacina, T. A., Cantrill, L. C., and Christodoulou, J. (2015). MeCP2 deficiency is associated with reduced levels of tubulin acetylation and can be restored using HDAC6 inhibitors. J. Mol. Med. (Berl.) 93, 63-72. doi: 10.1007/ s00109-014-1202-x

Guy, J., Gan, J., Selfridge, J., Cobb, S., and Bird, A. (2007). Reversal of neurological defects in a mouse model of Rett syndrome. Science 315, 1143-1147. doi: 10. 1126/science.1138389

Hagberg, B., Aicardi, J., Dias, K., and Ramos, O. (1983). A progressive syndrome of autism, dementia, ataxia, and loss of purposeful hand use in girls: Rett's syndrome: report of 35 cases. Ann. Neurol. 14, 471-479. doi: 10.1002/ana. 410140412

Hamberger, A., Gillberg, C., Palm, A., and Hagberg, B. (1992). Elevated CSF glutamate in Rett syndrome. Neuropediatrics 23, 212-213. doi: 10.1055/s-20081071344

He, L. J., Liu, N., Cheng, T. L., Chen, X. J., Li, Y. D., Shu, Y. S., et al. (2014) Conditional deletion of Mecp2 in parvalbumin-expressing GABAergic cells results in the absence of critical period plasticity. Nat. Commun. 5:5036. doi: $10.1038 /$ ncomms 6036

Hinz, L., Torrella Barrufet, J., and Heine, V. M. (2019). KCC2 expression levels are reduced in post mortem brain tissue of Rett syndrome patients. Acta Neuropathol. Commun. 7:196. doi: 10.1186/s40478-019-0852-x

Horská, A., Farage, L., Bibat, G., Nagae, L. M., Kaufmann, W. E., Barker, P. B., et al. (2009). Brain metabolism in Rett syndrome: age, clinical, and genotype correlations. Ann. Neurol. 65, 90-97. doi: 10.1002/ana. 21562

Horvath, P. M., and Monteggia, L. M. (2018). MeCP2 as an activator of gene expression. Trends Neurosci. 41, 72-74. doi: 10.1016/j.tins.2017.11.005

Howell, C. J., Sceniak, M. P., Lang, M., Krakowiecki, W., Abouelsoud, F. E., Lad, S. U., et al. (2017). Activation of the medial prefrontal cortex reverses cognitive and respiratory symptoms in a mouse model of Rett syndrome. eNeuro 4, 1-12. doi: 10.1523/eneuro.0277-17.2017

Hubbert, C., Guardiola, A., Shao, R., Kawaguchi, Y., Ito, A., Nixon, A., et al. (2002). HDAC6 is a microtubule-associated deacetylase. Nature 417, 455-458. doi: $10.1038 / 417455 a$

Hutchinson, A. N., Deng, J. V., Cohen, S., and West, A. E. (2012). Phosphorylation of MeCP2 at Ser421 contributes to chronic antidepressant action. J. Neurosci. 32, 14355-14363. doi: 10.1523/jneurosci.2156-12.2012

Ip, J. P. K., Mellios, N., and Sur, M. (2018). Rett syndrome: insights into genetic, molecular and circuit mechanisms. Nat. Rev. Neurosci. 19, 368-382. doi: 10. 1038/s41583-018-0006-3

Ito-Ishida, A., Ure, K., Chen, H., Swann, J. W., and Zoghbi, H. Y. (2015). Loss of MeCP2 in parvalbumin-and somatostatin-expressing neurons in mice leads to distinct rett syndrome-like phenotypes. Neuron 88, 651-658. doi: 10.1016/j. neuron.2015.10.029

Jackson, M. E., Homayoun, H., and Moghaddam, B. (2004). NMDA receptor hypofunction produces concomitant firing rate potentiation and burst activity reduction in the prefrontal cortex. Proc. Natl. Acad. Sci. U.S.A. 101, 8467-8472. doi: $10.1073 /$ pnas.0308455101

Janc, O. A., and Müller, M. (2014). The free radical scavenger Trolox dampens neuronal hyperexcitability, reinstates synaptic plasticity, and improves hypoxia tolerance in a mouse model of Rett syndrome. Front. Cell. Neurosci. 8:56. doi: 10.3389/fncel.2014.00056

Janc, O. A., Hüser, M. A., Dietrich, K., Kempkes, B., Menzfeld, C., Hülsmann, S., et al. (2016). Systemic radical scavenger treatment of a mouse model of Rett syndrome: merits and limitations of the vitamin e derivative trolox. Front. Cell. Neurosci. 10:266. doi: 10.3389/fncel.2016.00266

Jedlicka, P., Muellerleile, J., and Schwarzacher, S. W. (2018). Synaptic plasticity and excitation-inhibition balance in the dentate Gyrus: insights from In Vivo recordings in neuroligin-1, neuroligin-2, and Collybistin knockouts. Neural Plast. 2018:6015753. doi: 10.1155/2018/6015753
Jin, H. J., Pei, L., Li, Y. N., Zheng, H., Yang, S., Wan, Y., et al. (2017). Alleviative effects of fluoxetine on depressive-like behaviors by epigenetic regulation of BDNF gene transcription in mouse model of post-stroke depression. Sci. Rep. 7:14926. doi: 10.1038/s41598-017-13929-5

Jin, X., Cui, N., Zhong, W., Jin, X. T., and Jiang, C. (2013). GABAergic synaptic inputs of locus coeruleus neurons in wild-type and Mecp2-null mice. Am. J. Physiol. Cell Physiol. 304, C844-C857. doi: 10.1152/ajpcell.00399.2012

Johnson, C. M., Cui, N., Xing, H., Wu, Y., and Jiang, C. (2020). The antitussive cloperastine improves breathing abnormalities in a Rett Syndrome mouse model by blocking presynaptic GIRK channels and enhancing GABA release. Neuropharmacology 176:108214. doi: 10.1016/j.neuropharm.2020.108214

Johnson, R. A., Lam, M., Punzo, A. M., Li, H., Lin, B. R., Ye, K., et al. (2012). 7,8-dihydroxyflavone exhibits therapeutic efficacy in a mouse model of Rett syndrome. J. Appl. Physiol. (1985) 112, 704-710. doi: 10.1152/japplphysiol. 01361.2011

Jones, P. L., Veenstra, G. J., Wade, P. A., Vermaak, D., Kass, S. U., Landsberger, N., et al. (1998). Methylated DNA and MeCP2 recruit histone deacetylase to repress transcription. Nat. Genet. 19, 187-191. doi: 10.1038/561

Kahanovitch, U., Cuddapah, V. A., Pacheco, N. L., Holt, L. M., Mulkey, D. K., Percy, A. K., et al. (2018). MeCP2 deficiency leads to loss of Glial Kir4.1. eNeuro 5:0194-17. doi: 10.1523/eneuro.0194-17.2018

Kahanovitch, U., Patterson, K. C., Hernandez, R., and Olsen, M. L. (2019). Glial dysfunction in MeCP2 deficiency models: implications for Rett syndrome. Int. J. Mol. Sci. 20:3813. doi: 10.3390/ijms20153813

Katz, D. M. (2014). Brain-derived neurotrophic factor and Rett syndrome. Handb. Exp. Pharmacol. 220, 481-495. doi: 10.1007/978-3-642-45106-5_18

Kee, S. E., Mou, X., Zoghbi, H. Y., and Ji, D. (2018). Impaired spatial memory codes in a mouse model of Rett syndrome. Elife 7:e31451. doi: 10.7554/eLife.31451

Khwaja, O. S., Ho, E., Barnes, K. V., O’Leary, H. M., Pereira, L. M., Finkelstein, Y., et al. (2014). Safety, pharmacokinetics, and preliminary assessment of efficacy of mecasermin (recombinant human IGF-1) for the treatment of Rett syndrome. Proc. Natl. Acad. Sci. U.S.A. 111, 4596-4601. doi: 10.1073/pnas.1311141111

Kim, J. W., Autry, A. E., Na, E. S., Adachi, M., Björkholm, C., Kavalali, E. T., et al. (2021). Sustained effects of rapidly acting antidepressants require BDNFdependent MeCP2 phosphorylation. Nat. Neurosci. 24, 1100-1109. doi: 10. 1038/s41593-021-00868-8

Klar, R., Walker, A. G., Ghose, D., Grueter, B. A., Engers, D. W., Hopkins, C. R., et al. (2015). Activation of metabotropic glutamate receptor 7 is required for induction of long-term potentiation at SC-CA1 synapses in the hippocampus. J. Neurosci. 35, 7600-7615. doi: 10.1523/jneurosci.4543-14.2015

Kline, D. D., Ogier, M., Kunze, D. L., and Katz, D. M. (2010). Exogenous brainderived neurotrophic factor rescues synaptic dysfunction in Mecp2-null mice. J. Neurosci. 30, 5303-5310. doi: 10.1523/jneurosci.5503-09.2010

Krishnan, K., Lau, B. Y., Ewall, G., Huang, Z. J., and Shea, S. D. (2017). MECP2 regulates cortical plasticity underlying a learned behaviour in adult female mice. Nat. Commun. 8:14077. doi: 10.1038/ncomms 14077

Krishnan, K., Wang, B.-S., Lu, J., Wang, L., Maffei, A., Cang, J., et al. (2015). $\mathrm{MeCP} 2$ regulates the timing of critical period plasticity that shapes functional connectivity in primary visual cortex. Proc. Natl. Acad. Sci. U.S.A. 112, E4782E4791. doi: 10.1073/pnas.1506499112

Kron, M., Howell, C. J., Adams, I. T., Ransbottom, M., Christian, D., Ogier, M., et al. (2012). Brain activity mapping in Mecp2 mutant mice reveals functional deficits in forebrain circuits, including key nodes in the default mode network, that are reversed with ketamine treatment. J. Neurosci. 32, 13860-13872. doi: 10.1523/jneurosci.2159-12.2012

Lau, B. Y. B., Krishnan, K., Huang, Z. J., and Shea, S. D. (2020a). Maternal experience-dependent cortical plasticity in mice is circuit- and stimulus-specific and requires MECP2. J. Neurosci. 40, 1514-1526. doi: 10.1523/jneurosci.196419.2019

Lau, B. Y. B., Layo, D. E., Emery, B., Everett, M., Kumar, A., Stevenson, P., et al. (2020b). Lateralized expression of cortical perineuronal nets during maternal experience is dependent on MECP2. eNeuro 7, 1-20. doi: 10.1523/eneuro.050019.2020

Laurvick, C. L., de Klerk, N., Bower, C., Christodoulou, J., Ravine, D., Ellaway, C., et al. (2006). Rett syndrome in Australia: a review of the epidemiology. J. Pediatr. 148, 347-352. doi: 10.1016/j.jpeds.2005.10.037

Lebrun, N., Delépine, C., Selloum, M., Meziane, H., Nectoux, J., Herault, Y., et al. (2021). HDAC inhibitor ameliorates behavioral deficits in Mecp2(308/y) mouse 
model of Rett syndrome. Brain Res. 1772:147670. doi: 10.1016/j.brainres.2021. 147670

Lee, G. Y., and Han, S. N. (2018). The role of vitamin E in immunity. Nutrients 10:1614. doi: 10.3390/nu10111614

Lee, S., Kim, W., Ham, B.-J., Chen, W., Bear, M. F., and Yoon, B.-J. (2008). Activitydependent NR2B expression is mediated by MeCP2-dependent epigenetic regulation. Biochem. Biophys. Res. Commun. 377, 930-934. doi: 10.1016/j.bbrc. 2008.10.082

Lee, W., Kim, J., Yun, J.-M., Ohn, T., and Gong, Q. (2020). MeCP2 regulates gene expression through recognition of H3K27me3. Nat. Commun. 11:3140. doi: 10.1038/s41467-020-16907-0

Leung, J., McPhee, D. M., Renda, A., Penty, N., Farhoomand, F., Nashmi, R., et al. (2017). MeCP2-deficient mice have reduced $\alpha 4$ and $\alpha 6$ nicotinic receptor mRNA and altered behavioral response to nicotinic agonists. Behav. Brain Res. 330, 118-126. doi: 10.1016/j.bbr.2017.05.021

Li, J., Kells, P. A., Osgood, A. C., Gautam, S. H., and Shew, W. L. (2021). Collapse of complexity of brain and body activity due to excessive inhibition and MeCP2 disruption. Proc. Natl. Acad. Sci. U.S.A. 118:e2106378118. doi: 10.1073/pnas. 2106378118

Li, W., and Pozzo-Miller, L. (2012). Beyond widespread mecp2 deletions to model rett syndrome: conditional Spatio-temporal knockout, single-point mutations and transgenic rescue mice. Autism Open Access 2012(Suppl. 1):5. doi: 10.4172/ 2165-7890.S1-005

Li, W., and Pozzo-Miller, L. (2014). BDNF deregulation in Rett syndrome. Neuropharmacology 76(Pt. C), 737-746. doi: 10.1016/j.neuropharm.2013.03. 024

Li, W., Bellot-Saez, A., Phillips, M. L., Yang, T., Longo, F. M., and Pozzo-Miller, L. (2017). A small-molecule TrkB ligand restores hippocampal synaptic plasticity and object location memory in Rett syndrome mice. Dis. Model. Mech. 10, 837-845. doi: 10.1242/dmm.029959

Li, W., Calfa, G., Larimore, J., and Pozzo-Miller, L. (2012). Activity-dependent BDNF release and TRPC signaling is impaired in hippocampal neurons of Mecp2 mutant mice. Proc. Natl. Acad. Sci. U.S.A. 109, 17087-17092. doi: 10. 1073/pnas. 1205271109

Li, W., Xu, X., and Pozzo-Miller, L. (2016). Excitatory synapses are stronger in the hippocampus of Rett syndrome mice due to altered synaptic trafficking of AMPA-type glutamate receptors. Proc. Natl. Acad. Sci. U.S.A. 113, E1575E1584. doi: 10.1073/pnas.1517244113

Lioy, D. T., Garg, S. K., Monaghan, C. E., Raber, J., Foust, K. D., Kaspar, B. K., et al. (2011). A role for glia in the progression of Rett's syndrome. Nature 475, 497-500. doi: 10.1038/nature10214

Lozovaya, N., Nardou, R., Tyzio, R., Chiesa, M., Pons-Bennaceur, A., Eftekhari, S., et al. (2019). Early alterations in a mouse model of Rett syndrome: the GABA developmental shift is abolished at birth. Sci. Rep. 9:9276. doi: 10.1038/s41598019-45635-9

Lu, H., Ash, R. T., He, L., Kee, S. E., Wang, W., Yu, D., et al. (2016). Loss and gain of MeCP2 cause similar hippocampal circuit dysfunction that is rescued by deep brain stimulation in a rett syndrome mouse model. Neuron 91, 739-747. doi: 10.1016/j.neuron.2016.07.018

Lynch, G., and Gall, C. M. (2006). Ampakines and the threefold path to cognitive enhancement. Trends Neurosci. 29, 554-562. doi: 10.1016/j.tins.2006.07.007

Ma, D., Yoon, S.-I., Yang, C.-H., Marcy, G., Zhao, N., Leong, W.-Y., et al. (2015). Rescue of Methyl-CpG binding protein 2 dysfunction-induced defects in newborn neurons by pentobarbital. Neurotherapeutics 12, 477-490. doi: 10 . 1007/s13311-015-0343-0

Maffei, A., Charrier, C., Caiati, M. D., Barberis, A., Mahadevan, V., Woodin, M. A., et al. (2017). Emerging mechanisms underlying dynamics of GABAergic synapses. J. Neurosci. 37, 10792-10799. doi: 10.1523/jneurosci.1824-17. 2017

Maliszewska-Cyna, E., Bawa, D., and Eubanks, J. H. (2010). Diminished prevalence but preserved synaptic distribution of N-methyl-D-aspartate receptor subunits in the methyl $\mathrm{CpG}$ binding protein 2(MeCP2)-null mouse brain. Neuroscience 168, 624-632. doi: 10.1016/j.neuroscience.2010. 03.065

Marchetto, M. C., Carromeu, C., Acab, A., Yu, D., Yeo, G. W., Mu, Y., et al. (2010). A model for neural development and treatment of Rett syndrome using human induced pluripotent stem cells. Cell 143, 527-539. doi: 10.1016/j.cell.2010. 10.016
Marschik, P. B., Kaufmann, W. E., Sigafoos, J., Wolin, T., Zhang, D., Bartl-Pokorny, K. D., et al. (2013). Changing the perspective on early development of Rett syndrome. Res. Dev. Disabil. 34, 1236-1239. doi: 10.1016/j.ridd.2013.01.014

McGraw, C. M., Samaco, R. C., and Zoghbi, H. Y. (2011). Adult neural function requires MeCP2. Science 333:186. doi: 10.1126/science. 1206593

McLeod, F., Ganley, R., Williams, L., Selfridge, J., Bird, A., and Cobb, S. R. (2013). Reduced seizure threshold and altered network oscillatory properties in a mouse model of Rett syndrome. Neuroscience 231, 195-205. doi: 10.1016/j. neuroscience.2012.11.058

Medrihan, L., Tantalaki, E., Aramuni, G., Sargsyan, V., Dudanova, I., Missler, M., et al. (2008). Early defects of GABAergic synapses in the brain stem of a MeCP2 mouse model of Rett syndrome. J. Neurophysiol. 99, 112-121. doi: 10.1152/jn.00826.2007

Mierau, S. B., Patrizi, A., Hensch, T. K., and Fagiolini, M. (2016). Cell-specific regulation of N-Methyl-D-Aspartate receptor maturation by Mecp2 in cortical circuits. Biol. Psychiatry 79, 746-754. doi: 10.1016/j.biopsych.2015.05.018

Miranda-Lourenço, C., Ribeiro-Rodrigues, L., Fonseca-Gomes, J., Tanqueiro, S. R., Belo, R. F., Ferreira, C. B., et al. (2020). Challenges of BDNF-based therapies: from common to rare diseases. Pharmacol. Res. 162:105281. doi: 10.1016/j.phrs. 2020.105281

Morello, N., Schina, R., Pilotto, F., Phillips, M., Melani, R., Plicato, O., et al. (2018). Loss of Mecp2 causes atypical synaptic and molecular plasticity of parvalbuminexpressing interneurons reflecting Rett syndrome-like sensorimotor defects. eNeuro 5, 1-19. doi: 10.1523/eneuro.0086-18.2018

Moretti, P., Levenson, J. M., Battaglia, F., Atkinson, R., Teague, R., Antalffy, B., et al. (2006). Learning and memory and synaptic plasticity are impaired in a mouse model of Rett syndrome. J. Neurosci. 26, 319-327. doi: 10.1523/jneurosci.262305.2006

Murasawa, H., Kobayashi, H., Imai, J., Nagase, T., Soumiya, H., and Fukumitsu, H. (2021). Substantial acetylcholine reduction in multiple brain regions of Mecp2-deficient female rats and associated behavioral abnormalities. PLoS One 16:e0258830. doi: 10.1371/journal.pone.0258830

Naegelin, Y., Kuhle, J., Schädelin, S., Datta, A. N., Magon, S., Amann, M., et al. (2021). Fingolimod in children with Rett syndrome: the FINGORETT study. Orphanet J. Rare Dis. 16:19. doi: 10.1186/s13023-020-01655-7

Nan, X., Campoy, F. J., and Bird, A. (1997). MeCP2 is a transcriptional repressor with abundant binding sites in genomic chromatin. Cell 88, 471-481. doi: 10.1016/s0092-8674(00)81887-5

Nelson, E. D., Bal, M., Kavalali, E. T., and Monteggia, L. M. (2011). Selective impact of MeCP2 and associated histone deacetylases on the dynamics of evoked excitatory neurotransmission. J. Neurophysiol. 106, 193-201. doi: 10.1152/jn. 00751.2010

Nelson, E. D., Kavalali, E. T., and Monteggia, L. M. (2006). MeCP2-dependent transcriptional repression regulates excitatory neurotransmission. Curr. Biol. 16, 710-716. doi: 10.1016/j.cub.2006.02.062

Neul, J. L., Kaufmann, W. E., Glaze, D. G., Christodoulou, J., Clarke, A. J., Bahi-Buisson, N., et al. (2010). Rett syndrome: revised diagnostic criteria and nomenclature. Ann. Neurol. 68, 944-950. doi: 10.1002/ana.22124

Nguyen, M. V. C., Du, F., Felice, C. A., Shan, X., Nigam, A., Mandel, G., et al. (2012) $\mathrm{MeCP} 2$ is critical for maintaining mature neuronal networks and global brain anatomy during late stages of postnatal brain development and in the mature adult brain. J. Neurosci. 32, 10021-10034. doi: 10.1523/jneurosci.1316-12.2012

Nibuya, M., Morinobu, S., and Duman, R. S. (1995). Regulation of BDNF and trkB mRNA in rat brain by chronic electroconvulsive seizure and antidepressant drug treatments. J. Neurosci. 15, 7539-7547. doi: 10.1523/jneurosci.15-1107539.1995

Niciu, M. J., Kelmendi, B., and Sanacora, G. (2012). Overview of glutamatergic neurotransmission in the nervous system. Pharmacol. Biochem. Behav. 100, 656-664. doi: 10.1016/j.pbb.2011.08.008

Noutel, J., Hong, Y. K., Leu, B., Kang, E., and Chen, C. (2011). Experiencedependent retinogeniculate synapse remodeling is abnormal in MeCP2deficient mice. Neuron 70, 35-42. doi: 10.1016/j.neuron.2011.03.001

Ogier, M., Wang, H., Hong, E., Wang, Q., Greenberg, M. E., and Katz, D. M. (2007). Brain-derived neurotrophic factor expression and respiratory function improve after ampakine treatment in a mouse model of Rett syndrome. J. Neurosci. 27, 10912-10917. doi: 10.1523/jneurosci.1869-07.2007

Oginsky, M. F., Cui, N., Zhong, W., Johnson, C. M., and Jiang, C. (2014). Alterations in the cholinergic system of brain stem neurons in a mouse model 
of Rett syndrome. Am. J. Physiol. Cell Physiol. 307, C508-C520. doi: 10.1152/ ajpcell.00035.2014

Oh, W. C., and Smith, K. R. (2019). Activity-dependent development of GABAergic synapses. Brain Res. 1707, 18-26. doi: 10.1016/j.brainres.2018.11.014

Okuda, K., Kobayashi, S., Fukaya, M., Watanabe, A., Murakami, T., Hagiwara, M., et al. (2017). CDKL5 controls postsynaptic localization of GluN2B-containing NMDA receptors in the hippocampus and regulates seizure susceptibility. Neurobiol. Dis. 106, 158-170. doi: 10.1016/j.nbd.2017.07.002

O’Leary, H. M., Kaufmann, W. E., Barnes, K. V., Rakesh, K., Kapur, K., Tarquinio, D. C., et al. (2018). Placebo-controlled crossover assessment of mecasermin for the treatment of Rett syndrome. Ann. Clin. Transl. Neurol. 5, 323-332. doi: $10.1002 / \mathrm{acn} 3.533$

Oyarzabal, A., Xiol, C., Castells, A. A., Grau, C., O'Callaghan, M., Fernández, G., et al. (2020). Comprehensive analysis of GABA(A)-A1R developmental alterations in Rett syndrome: setting the focus for therapeutic targets in the time frame of the disease. Int. J. Mol. Sci. 21:518. doi: 10.3390/ijms21020518

Patrizi, A., Awad, P. N., Chattopadhyaya, B., Li, C., Di Cristo, G., and Fagiolini, M. (2020). Accelerated hyper-maturation of parvalbumin circuits in the absence of MeCP2. Cereb. Cortex 30, 256-268. doi: 10.1093/cercor/bhz085

Patrizi, A., Picard, N., Simon, A. J., Gunner, G., Centofante, E., Andrews, N. A., et al. (2016). Chronic administration of the N-Methyl-D-aspartate receptor antagonist ketamine improves rett syndrome phenotype. Biol. Psychiatry 79, 755-764. doi: 10.1016/j.biopsych.2015.08.018

Persico, A. M., Ricciardello, A., and Cucinotta, F. (2019). The psychopharmacology of autism spectrum disorder and Rett syndrome. Handb. Clin. Neurol. 165, 391-414. doi: 10.1016/b978-0-444-64012-3.00024-1

Phillips, M. L., Robinson, H. A., and Pozzo-Miller, L. (2019). Ventral hippocampal projections to the medial prefrontal cortex regulate social memory. Elife 8:e44182. doi: 10.7554/eLife.44182

Pini, G., Congiu, L., Benincasa, A., DiMarco, P., Bigoni, S., Dyer, A. H., et al. (2016). Illness severity, social and cognitive ability, and EEG analysis of ten patients with Rett syndrome treated with mecasermin (recombinant human IGF-1). Autism Res. Treat. 2016:5073078. doi: 10.1155/2016/5073078

Pizzo, R., Gurgone, A., Castroflorio, E., Amendola, E., Gross, C., Sassoè-Pognetto, M., et al. (2016). Lack of Cdkl5 disrupts the organization of excitatory and inhibitory synapses and parvalbumin interneurons in the primary visual cortex. Front. Cell. Neurosci. 10:261. doi: 10.3389/fncel.2016.00261

Qiu, Z., Sylwestrak, E. L., Lieberman, D. N., Zhang, Y., Liu, X.-Y., and Ghosh, A. (2012). The Rett syndrome protein MeCP2 regulates synaptic scaling. J. Neurosci. 32, 989-994. doi: 10.1523/jneurosci.0175-11.2012

Reichelt, A. C., Hare, D. J., Bussey, T. J., and Saksida, L. M. (2019). Perineuronal nets: plasticity, protection, and therapeutic potential. Trends Neurosci. 42, 458-470. doi: 10.1016/j.tins.2019.04.003

Ribeiro, M. C., and MacDonald, J. L. (2020). Sex differences in Mecp2-mutant Rett syndrome model mice and the impact of cellular mosaicism in phenotype development. Brain Res. 1729:146644. doi: 10.1016/j.brainres.2019.146644

Ricceri, L., De Filippis, B., Fuso, A., and Laviola, G. (2011). Cholinergic hypofunction in MeCP2-308 mice: beneficial neurobehavioural effects of neonatal choline supplementation. Behav. Brain Res. 221, 623-629. doi: 10. 1016/j.bbr.2011.03.051

Ricciardi, S., Boggio, E. M., Grosso, S., Lonetti, G., Forlani, G., Stefanelli, G., et al. (2011). Reduced AKT/mTOR signaling and protein synthesis dysregulation in a Rett syndrome animal model. Hum. Mol. Genet. 20, 1182-1196. doi: 10.1093/ $\mathrm{hmg} / \mathrm{ddq} 563$

Riikonen, R. (2016). Treatment of autistic spectrum disorder with insulin-like growth factors. Eur. J. Paediatr. Neurol. 20, 816-823. doi: 10.1016/j.ejpn.2016. 08.005

Robinson, L., Guy, J., McKay, L., Brockett, E., Spike, R. C., Selfridge, J., et al. (2012). Morphological and functional reversal of phenotypes in a mouse model of Rett syndrome. Brain 135(Pt. 9), 2699-2710. doi: 10.1093/brain/aws096

Roux, J. C., Dura, E., Moncla, A., Mancini, J., and Villard, L. (2007). Treatment with desipramine improves breathing and survival in a mouse model for Rett syndrome. Eur. J. Neurosci. 25, 1915-1922. doi: 10.1111/j.1460-9568.2007. 05466.x

Samaco, R. C., Hogart, A., and LaSalle, J. M. (2004). Epigenetic overlap in autismspectrum neurodevelopmental disorders: MECP2 deficiency causes reduced expression of UBE3A and GABRB3. Hum. Mol. Genet. 14, 483-492. doi: 10. 1093/hmg/ddi045
Sceniak, M. P., Lang, M., Enomoto, A. C., James Howell, C., Hermes, D. J., and Katz, D. M. (2016). Mechanisms of functional hypoconnectivity in the medial prefrontal cortex of Mecp2 null mice. Cereb. Cortex 26, 1938-1956. doi: 10.1093/cercor/bhv002

Schmid, D. A., Yang, T., Ogier, M., Adams, I., Mirakhur, Y., Wang, Q., et al. (2012). A TrkB small molecule partial agonist rescues TrkB phosphorylation deficits and improves respiratory function in a mouse model of Rett syndrome. J. Neurosci. 32, 1803-1810. doi: 10.1523/jneurosci.0865-11.2012

Schuman, E. M. (1999). Neurotrophin regulation of synaptic transmission. Curr. Opin. Neurobiol. 9, 105-109. doi: 10.1016/s0959-4388(99)80013-0

Sigal, Y. M., Bae, H., Bogart, L. J., Hensch, T. K., and Zhuang, X. (2019). Structural maturation of cortical perineuronal nets and their perforating synapses revealed by superresolution imaging. Proc. Natl. Acad. Sci. U.S.A. 116, 7071-7076. doi: $10.1073 /$ pnas. 1817222116

Stettner, G. M., Huppke, P., Brendel, C., Richter, D. W., Gärtner, J., and Dutschmann, M. (2007). Breathing dysfunctions associated with impaired control of postinspiratory activity in Mecp2-/y knockout mice. J. Physiol. 579(Pt. 3), 863-876. doi: 10.1113/jphysiol.2006.119966

Sun, Y., Gao, Y., Tidei, J. J., Shen, M., Hoang, J. T., Wagner, D. F., et al. (2018). Loss of MeCP2 in immature neurons leads to impaired network integration. Hum. Mol. Genet. 28, 245-257. doi: 10.1093/hmg/ddy338

Taneja, P., Ogier, M., Brooks-Harris, G., Schmid, D. A., Katz, D. M., and Nelson, S. B. (2009). Pathophysiology of locus ceruleus neurons in a mouse model of rett syndrome. J. Neurosci. 29, 12187-12195. doi: 10.1523/jneurosci.3156-09. 2009

Tang, X., Drotar, J., Li, K., Clairmont, C. D., Brumm, A. S., Sullins, A. J., et al. (2019). Pharmacological enhancement of KCC2 gene expression exerts therapeutic effects on human Rett syndrome neurons and Mecp2 mutant mice. Sci. Transl. Med. 11:eaau0164. doi: 10.1126/scitranslmed.aau0164

Tang, X., Kim, J., Zhou, L., Wengert, E., Zhang, L., Wu, Z., et al. (2016). KCC2 rescues functional deficits in human neurons derived from patients with Rett syndrome. Proc. Natl. Acad. Sci. U.S.A. 113, 751-756. doi: 10.1073/pnas. 1524013113

Travaglione, S., Loizzo, S., Rizza, T., Del Brocco, A., Ballan, G., Guidotti, M., et al. (2014). Enhancement of mitochondrial ATP production by the Escherichia coli cytotoxic necrotizing factor 1 . FEBS J. 281, 3473-3488. doi: 10.1111/febs.12874

Tropea, D., Giacometti, E., Wilson, N. R., Beard, C., McCurry, C., Fu, D. D., et al. (2009). Partial reversal of Rett Syndrome-like symptoms in MeCP2 mutant mice. Proc. Natl. Acad. Sci. U.S.A. 106, 2029-2034. doi: 10.1073/pnas. 0812394106

Turrigiano, G. G., and Nelson, S. B. (2004). Homeostatic plasticity in the developing nervous system. Nat. Rev. Neurosci. 5, 97-107. doi: 10.1038/nrn 1327

Urbinati, C., Cosentino, L., Germinario, E. A. P., Valenti, D., Vigli, D., Ricceri, L., et al. (2021). Treatment with the bacterial toxin CNF1 selectively rescues cognitive and brain mitochondrial deficits in a female mouse model of rett syndrome carrying a MeCP2-null mutation. Int. J. Mol. Sci. 22:6739. doi: 10. 3390/ijms 22136739

Ure, K., Lu, H., Wang, W., Ito-Ishida, A., Wu, Z., He, L. J., et al. (2016). Restoration of Mecp2 expression in GABAergic neurons is sufficient to rescue multiple disease features in a mouse model of Rett syndrome. Elife 5:e14198. doi: 10. 7554/eLife. 14198

Villani, C., Carli, M., Castaldo, A. M., Sacchetti, G., and Invernizzi, R. W. (2021). Fluoxetine increases brain MeCP2 immuno-positive cells in a female Mecp2 heterozygous mouse model of Rett syndrome through endogenous serotonin. Sci. Rep. 11:14690. doi: 10.1038/s41598-021-94156-x

Villani, C., Sacchetti, G., Carli, M., and Invernizzi, R. W. (2020). Fluoxetine rescues rotarod motor deficits in Mecp2 heterozygous mouse model of Rett syndrome via brain serotonin. Neuropharmacology 176:108221. doi: 10.1016/ j.neuropharm.2020.108221

Voituron, N., and Hilaire, G. (2011). The benzodiazepine Midazolam mitigates the breathing defects of Mecp2-deficient mice. Respir. Physiol. Neurobiol. 177, 56-60. doi: 10.1016/j.resp.2011.02.002

Watanabe, M., and Fukuda, A. (2015). Development and regulation of chloride homeostasis in the central nervous system. Front. Cell. Neurosci. 9:371. doi: 10.3389/fncel.2015.00371

Weng, S. M., McLeod, F., Bailey, M. E., and Cobb, S. R. (2011). Synaptic plasticity deficits in an experimental model of rett syndrome: long-term potentiation 
saturation and its pharmacological reversal. Neuroscience 180, 314-321. doi: 10.1016/j.neuroscience.2011.01.061

Wenk, G. L. (1997). Rett syndrome: neurobiological changes underlying specific symptoms. Prog. Neurobiol. 51, 383-391. doi: 10.1016/s0301-0082(96)00059-7

Wenk, G. L., and Hauss-Wegrzyniak, B. (1999). Altered cholinergic function in the basal forebrain of girls with Rett syndrome. Neuropediatrics 30, 125-129. doi: $10.1055 /$ s-2007-973476

Wenk, G. L., and Mobley, S. L. (1996). Choline acetyltransferase activity and vesamicol binding in Rett syndrome and in rats with nucleus basalis lesions. Neuroscience 73, 79-84. doi: 10.1016/0306-4522(96)0 0019-x

Wood, L., Gray, N. W., Zhou, Z., Greenberg, M. E., and Shepherd, G. M. (2009). Synaptic circuit abnormalities of motor-frontal layer $2 / 3$ pyramidal neurons in an RNA interference model of methyl-CpG-binding protein 2 deficiency. J. Neurosci. 29, 12440-12448. doi: 10.1523/jneurosci.3321-09.2009

Wu, Y., Cui, N., Xing, H., Zhong, W., Arrowood, C., Johnson, C. M., et al. (2021). In vivo evidence for the cellular basis of central hypoventilation of Rett syndrome and pharmacological correction in the rat model. J. Cell. Physiol. 236, 8082-8098. doi: 10.1002/jcp.30462

Xing, H., Cui, N., Johnson, C. M., Faisthalab, Z., and Jiang, C. (2021). Dual synaptic inhibitions of brainstem neurons by GABA and glycine with impact on Rett syndrome. J. Cell. Physiol. 236, 3615-3628. doi: 10.1002/jcp.30098

Xu, X., and Pozzo-Miller, L. (2017). EEA1 restores homeostatic synaptic plasticity in hippocampal neurons from Rett syndrome mice. J. Physiol. 595, 5699-5712. doi: 10.1113/jp274450

Yagasaki, Y., Miyoshi, G., and Miyata, M. (2018). Experience-dependent MeCP2 expression in the excitatory cells of mouse visual thalamus. PLoS One 13:e0198268. doi: 10.1371/journal.pone.0198268

Yuan, Z. F., Mao, S. S., Shen, J., Jiang, L. H., Xu, L., Xu, J. L., et al. (2020). Insulin-Like growth factor-1 down-regulates the phosphorylation of FXYD1 and rescues behavioral deficits in a mouse model of Rett syndrome. Front. Neurosci. 14:20. doi: 10.3389/fnins.2020.00020

Zanella, S., Mebarek, S., Lajard, A. M., Picard, N., Dutschmann, M., and Hilaire, G. (2008). Oral treatment with desipramine improves breathing and life span in Rett syndrome mouse model. Respir. Physiol. Neurobiol. 160, 116-121. doi: 10.1016/j.resp.2007.08.009

Zhang, L., He, J., Jugloff, D. G., and Eubanks, J. H. (2008). The MeCP2null mouse hippocampus displays altered basal inhibitory rhythms and is prone to hyperexcitability. Hippocampus 18, 294-309. doi: 10.1002/hipo. 20389

Zhang, W., Peterson, M., Beyer, B., Frankel, W. N., and Zhang, Z.-w. (2014). Loss of $\mathrm{MeCP} 2$ from forebrain excitatory neurons leads to cortical hyperexcitation and seizures. J. Neurosci. 34, 2754-2763. doi: 10.1523/jneurosci.4900-12. 2014

Zhang, Y., Cao, S. X., Sun, P., He, H. Y., Yang, C. H., Chen, X. J., et al. (2016). Loss of MeCP2 in cholinergic neurons causes part of RTT-like phenotypes via $\alpha 7$ receptor in hippocampus. Cell Res. 26, 728-742. doi: 10.1038/cr.2016.48

Zhang, Y., Zhu, Y., Cao, S. X., Sun, P., Yang, J. M., Xia, Y. F., et al. (2020). MeCP2 in cholinergic interneurons of nucleus accumbens regulates fear learning. Elife 9:e55342. doi: 10.7554/eLife.55342

Zhong, W., Cui, N., Jin, X., Oginsky, M. F., Wu, Y., Zhang, S., et al. (2015). Methyl CpG binding protein 2 gene disruption augments tonic currents of $\gamma$-aminobutyric acid receptors in locus coeruleus neurons: IMPACT ON NEURONAL EXCITABILITY AND BREATHING. J. Biol. Chem. 290, 1840018411. doi: 10.1074/jbc.M115.650465

Zhong, W., Johnson, C. M., Wu, Y., Cui, N., Xing, H., Zhang, S., et al. (2016). Effects of early-life exposure to THIP on phenotype development in a mouse model of Rett syndrome. J. Neurodev. Disord. 8:37. doi: 10.1186/s11689-016-9169-2

Zhong, X., Li, H., and Chang, Q. (2012). MeCP2 phosphorylation is required for modulating synaptic scaling through mGluR5. J. Neurosci. 32, 12841-12847. doi: 10.1523/jneurosci.2784-12.2012

Zhou, H., Wu, W., Zhang, Y., He, H., Yuan, Z., Zhu, Z., et al. (2017). Selective preservation of cholinergic MeCP2 rescues specific Rett-syndromelike phenotypes in MeCP2(stop) mice. Behav. Brain Res. 322(Pt. A), 51-59. doi: 10.1016/j.bbr.2017.01.023

Zucker, R. S., and Regehr, W. G. (2002). Short-term synaptic plasticity. Annu. Rev. Physiol. 64, 355-405. doi: 10.1146/annurev.physiol.64.092501.114547

Conflict of Interest: The author declares that the research was conducted in the absence of any commercial or financial relationships that could be construed as a potential conflict of interest.

Publisher's Note: All claims expressed in this article are solely those of the authors and do not necessarily represent those of their affiliated organizations, or those of the publisher, the editors and the reviewers. Any product that may be evaluated in this article, or claim that may be made by its manufacturer, is not guaranteed or endorsed by the publisher.

Copyright (c) $2022 \mathrm{Li}$. This is an open-access article distributed under the terms of the Creative Commons Attribution License (CC BY). The use, distribution or reproduction in other forums is permitted, provided the original author(s) and the copyright owner(s) are credited and that the original publication in this journal is cited, in accordance with accepted academic practice. No use, distribution or reproduction is permitted which does not comply with these terms. 